\title{
Response of North Atlantic Ocean Circulation to Atmospheric Weather Regimes
}

\author{
NICOLAS BARRIER \\ Laboratoire de Physique des Oceans, UMR 6523, CNRS/Ifremer/UBO/IRD, Brest, France \\ CHRISTOPHE CASSOU \\ CNRS Cerfacs, Toulouse, France \\ Julie Deshayes AND ANNe-MARIE TREguier \\ Laboratoire de Physique des Oceans, UMR 6523, CNRS/Ifremer/UBO/IRD, Brest, France
}

(Manuscript received 7 November 2012, in final form 13 September 2013)

\begin{abstract}
A new framework is proposed for investigating the atmospheric forcing of North Atlantic Ocean circulation. Instead of using classical modes of variability, such as the North Atlantic Oscillation (NAO) or the east Atlantic pattern, the weather regimes paradigm was used. Using this framework helped avoid problems associated with the assumptions of orthogonality and symmetry that are particular to modal analysis and known to be unsuitable for the NAO. Using ocean-only historical and sensitivity experiments, the impacts of the four winter weather regimes on horizontal and overturning circulations were investigated. The results suggest that the Atlantic Ridge (AR), negative NAO $\left(\mathrm{NAO}^{-}\right)$, and positive NAO $\left(\mathrm{NAO}^{+}\right)$regimes induce a fast (monthly-to-interannual time scales) adjustment of the gyres via topographic Sverdrup dynamics and of the meridional overturning circulation via anomalous Ekman transport. The wind anomalies associated with the Scandinavian blocking regime (SBL) are ineffective in driving a fast wind-driven oceanic adjustment. The response of both gyre and overturning circulations to persistent regime conditions was also estimated. AR causes a strong, wind-driven reduction in the strengths of the subtropical and subpolar gyres, while $\mathrm{NAO}^{+}$ causes a strengthening of the subtropical gyre via wind stress curl anomalies and of the subpolar gyre via heat flux anomalies. $\mathrm{NAO}^{-}$induces a southward shift of the gyres through the southward displacement of the wind stress curl. The SBL is found to impact the subpolar gyre only via anomalous heat fluxes. The overturning circulation is shown to spin up following persistent SBL and $\mathrm{NAO}^{+}$and to spin down following persistent $\mathrm{AR}$ and $\mathrm{NAO}^{-}$conditions. These responses are driven by changes in deep water formation in the Labrador Sea.
\end{abstract}

\section{Introduction}

A large part of the atmospheric variability in the North Atlantic-Europe (NAE) domain is controlled by the North Atlantic Oscillation (NAO; Hurrell 1995). The NAO is traditionally defined either as an index (normalized pressure difference between the Azores high and the Icelandic low atmospheric pressure centers) or by the first empirical orthogonal function (EOF) of the mean sea level pressure (MSLP) or geopotential height anomalies over the North Atlantic domain. MSLP fluctuations between the Azores high and the Icelandic low are accompanied by changes in midlatitude westerlies and

Corresponding author address: Nicolas Barrier, LPO, UMR 6523, CNRS/Ifremer/UBO/IRD, Pointe du Diable, 29280 Plouzané, France. E-mail: nicolas.barrier@ifremer.fr trade winds that are strengthened during positive NAO conditions, and conversely during negative NAO. These changes have been shown to strongly impact the ocean circulation in the North Atlantic.

Several modeling and observational studies suggest that the oceanic response to NAO fluctuations depends on the time scales. At monthly-to-interannual time scales, the ocean primarily responds to related changes in wind intensity and position. Positive NAO phases generate anticyclonic gyre circulation anomalies situated at the boundary between the subtropical and subpolar gyres [called the "intergyre gyre" following Marshall et al. (2001)]. Concurrently, the NAO alters the meridional overturning circulation (MOC), creating a dipolar anomaly pattern with a weakening north of $40^{\circ} \mathrm{N}$ and a strengthening to the south. This dipole is generated by anomalous Ekman transport (Eden and 
Willebrand 2001; Bellucci et al. 2008): strengthened westerlies generate southward Ekman transport anomalies along the $40^{\circ}-60^{\circ} \mathrm{N}$ latitudinal band, while strengthened trade winds to the south generate northward Ekman transport anomalies, causing convergence at $40^{\circ} \mathrm{N}$ and a subsequent dipole.

At decadal time scales, positive NAO conditions lead to an intensification of both subtropical and subpolar gyres via baroclinic adjustment (Eden and Willebrand 2001; Lohmann et al. 2009; Zhu and Demirov 2011), while the MOC undergoes basinwide strengthening driven by increased heat loss in the Labrador Sea and subsequent changes in deep convection (Eden and Willebrand 2001; Curry and McCartney 2001; Lohmann et al. 2009).

While the impact of the NAO on ocean circulation has been widely studied, only a few studies have investigated the impacts of the other modes of atmospheric variability, such as the east Atlantic pattern (EAP) or the Scandinavian pattern (SCAN), descriptions of which can be found in Barnston and Livezey (1987). Msadek and Frankignoul (2009) and Ruprich-Robert and Cassou (2013), using a control simulation of L'Institut Pierre-Simon Laplace Coupled Model, version 4 (IPSLCM4), and of the Centre National de Recherches Météorologiques Coupled Global Climate Model, version 5 (CNRM-CM5), respectively, suggest that the MOC multidecadal variability could be closely related to the EAP. In their models, the EAP induces anomalous advection of salinity that impacts deep convection in the Nordic seas, driving MOC changes. Medhaug et al. (2012) found that in the Bergen Climate Model control simulation, convection in the Labrador Sea accounts for onethird of North Atlantic Deep Water transport, while the remaining two-thirds originate from the GreenlandScotland Ridge overflows. They argue that convection in the Labrador Sea is correlated with the NAO, while water mass exchange across the Greenland-Scotland Ridge is correlated with the SCAN index. Using the same experiment, Langehaug et al. (2012) suggest that the strength of the subpolar gyre is significantly correlated with the EAP index. Altogether, these findings suggest that the EAP and the SCAN might be as important as the NAO in forcing the ocean circulation in the North Atlantic on seasonal-to-decadal time scales. However, these studies rely on coupled climate models that undergo many biases [mean position of the North Atlantic Current (NAC), unrealistic deep convection]. It is therefore of interest to perform sensitivity experiments using forced ocean models, because they better reproduce the ocean variability as compared to coupled climate models, although they are limited by the absence of coupling at the air-sea interface (Griffies et al. 2009).
The important role of the EAP on the horizontal circulation has been confirmed in recent observational studies. Häkkinen et al. (2011a,b) suggest that the NAO alone is not enough to gain an understanding of the observed warming and salinization in the eastern subpolar gyre in the mid-1990s. They attribute the latter to decadal fluctuations in the occurrence of winter blocking conditions, assessed through traditional atmospheric metrics based on daily variance of MSLP anomalies (Scherrer et al. 2006). The space-time structure of wind anomalies associated with blocking conditions, which Häkkinen et al. (2011a) introduce as the gyre mode, in fact projects very well onto the EAP: when the EAP is positive, the subpolar gyre weakens and shrinks; despite slackened circulation, this facilitates the northward penetration of warm, salty subtropical water into the eastern subpolar gyre (Hátún et al. 2005).

The aforementioned studies typically diagnosed the atmospheric variability by decomposing it into modes of variability, using methods such as EOF. These methods have some limitations, insofar as they assume orthogonality and spatial symmetry of the modes. The latter assumption has been shown to be partially inadequate for the NAO (Cassou et al. 2004), where the deeper Icelandic low/stronger Azores high are northeastward shifted in positive $\left(\mathrm{NAO}^{+}\right)$compared to negative NAO $\left(\mathrm{NAO}^{-}\right)$. Additionally, EOF decomposition assumes that both phases of the modes exist in nature, which may not be the case for the SCAN pattern that is linked to blocking conditions controlled by nonlinear eddy-mean flow interactions. These limitations of EOF-derived modes of variability can potentially lead to misinterpretation of atmospheric variability and, as a consequence, of the associated ocean response. To avoid those constraints, the so-called weather regimes (WRs) paradigm is an alternative method. The regimes are large-scale, recurrent, and quasi-stationary atmospheric patterns computed from daily atmospheric circulation anomalies (e.g., Vautard 1990). Within this framework, Cassou et al. (2004) document the spatial asymmetry of the NAO dynamics and better isolate the blocking conditions characterized by high pressure anomalies over Scandinavia and low pressure anomalies over the Labrador Sea. They found four typical regimes in winter: $\mathrm{NAO}^{+}, \mathrm{NAO}^{-}$, Scandinavian blocking regime [SBL; as used in Vautard (1990)] and Atlantic Ridge (AR). AR is characterized by anticyclonic sea level pressure anomalies in the North Atlantic, while SBL is characterized by anticyclonic conditions over Europe and cyclonic conditions over Greenland. In a previous study, we have used the WR decomposition to investigate the impacts of the related atmospheric forcing on the variability of the subtropical gyre intensity based on 
observed sea surface height anomalies (Barrier et al. 2013). We suggested that the two NAO-related regimes have very little impact on the subtropical gyre strength as compared to AR (which can be viewed as a positive EAP phase), whose associated wind stress curl anomalies induce barotropic (Sverdrup like) and baroclinic (westward propagation of planetary waves) sea level anomalies.

The findings of Barrier et al. (2013) are consistent with the results of Häkkinen et al. (2011a), though it should be noted that the methods of Barrier et al. (2013) were restricted to an analysis of the subtropical gyre response to atmospheric variability at 0 -yr lag only. The aim of the present study is to extend the analysis of Barrier et al. (2013) by investigating the response of the horizontal and overturning components of the circulation to the four NAE WRs using a forced realistic ocean model. The questions of what are the impacts of each WR on both the horizontal and overturning circulations as a function of time scale and what are the physical mechanisms involved were addressed. To answer these questions, North Atlantic Ocean horizontal and meridional circulation anomalies in a historical ocean simulation (forced with interannually varying atmosphere) are investigated in response to the variability of the WRs. Sensitivity experiments, in which the model is forced with heat and momentum fluxes that correspond to a given WR, are then performed to isolate the role of the WRs on ocean circulation.

The paper is organized as follows. Section 2 describes the North Atlantic WR paradigm. Section 3 describes the numerical model and the atmospheric forcings used in this study. Section 4 investigates the variability of the historical experiment in relation to observed WR changes. Section 5 describes the sensitivity experiments and addresses the impact of each WR taken separately on ocean circulation. The discussion and conclusions are provided in sections 6 and 7, respectively.

\section{North Atlantic weather regimes}

Spatial and temporal characteristics of the NAE WRs as well as their statistical and physical properties have been described in detail in Cassou et al. (2011) and Barrier et al. (2013). In this study, we use the same approach as in Barrier et al. (2013)-limiting our analyses to the winter season [i.e., December-March (DJFM)]. However, the time period over which WRs are determined from the National Centers for Environmental Prediction-National Center for Atmospheric Research (NCEP-NCAR) reanalysis (Kalnay et al. 1996) starts 1 December 1957 here instead of 1 December 1948 as in Barrier et al. (2013). This choice has been made because we here also use forcing datasets spanning the 40-yr period (1958-2002) of the European Centre for MediumRange Weather Forecasts (ECMWF) Re-Analysis (ERA-40). The four regimes considered in this study are the AR, which is characterized by anticyclonic anomalies in the center of the subpolar gyre; the SBL, characterized by anticyclonic anomalies over Europe and cyclonic anomalies over Greenland; and the two NAO phases $\left(\mathrm{NAO}^{-}\right.$and $\left.\mathrm{NAO}^{+}\right)$. In this paper, we only discuss the wind stress curl, Ekman transport, and air temperature anomalies associated with the weather regimes, because we expect them to play the major roles in driving ocean circulation. The reader is referred to Cassou et al. (2011) for a complete description of the WR-related surface ocean variables.

Anomalous daily maps of meridional wind, zonal wind, and air temperature anomalies from NCEPNCAR are computed by removing a smoothed seasonal cycle (two harmonics retained). Anomalous Ekman transport and wind stress curl anomalies, averaged over the days attributed to each WR, are shown in Fig. 1. AR is characterized by negative (anticyclonic) wind stress curl anomalies north of $40^{\circ} \mathrm{N}$ and positive (cyclonic) anomalies to the south. Ekman transport anomalies are northward from $30^{\circ}$ to $50^{\circ} \mathrm{N}$ and southward in the Irminger and Norwegian Seas, leading to transport convergence at the center of the AR anticyclone. SBL is characterized by weaker anomalies, except along the East Greenland Current location, where anomalies are positive. Regarding $\mathrm{NAO}^{-}$curl anomalies, strong zonal positive anomalies between $30^{\circ}$ and $55^{\circ} \mathrm{N}$ dominate, while strong negative anomalies prevail to the north of $60^{\circ} \mathrm{N}$ and expand from the eastern side of the Labrador Sea to the Norwegian sea, encompassing the Irminger Basin. The $\mathrm{NAO}^{-}$Ekman transport anomalies diverge near $45^{\circ} \mathrm{N}$. Curl anomalies for $\mathrm{NAO}^{+}$are very different from those of $\mathrm{NAO}^{-}$. With $\mathrm{NAO}^{+}$, the positive anomalies in the northeastern subpolar gyre are tilted southeastward and almost vanish in the Labrador Sea. The Ekman transport anomalies for $\mathrm{NAO}^{+}$converge around $40^{\circ} \mathrm{N}$. Strong and zonally extended anomalies mark AR, $\mathrm{NAO}^{-}$, and $\mathrm{NAO}^{+}$and they are expected to have a significant wind-driven impact on both horizontal and meridional ocean circulations.

Figure 2 shows the daily air temperature anomaly composites associated with the weather regimes. In the Labrador Sea, colder-than-average temperatures occur for $\mathrm{SBL}$ and $\mathrm{NAO}^{+}$, while the anomalies are positive for $\mathrm{NAO}^{-}$. For AR, positive anomalies are located in the center of the subpolar gyre. These temperature anomalies can be viewed as a proxy for anomalous downward (i.e., into the ocean) heat fluxes. As convection and deep water formation in the Labrador Sea are primarily driven by anomalous heat fluxes (Straneo 2006), buoyancy-driven 

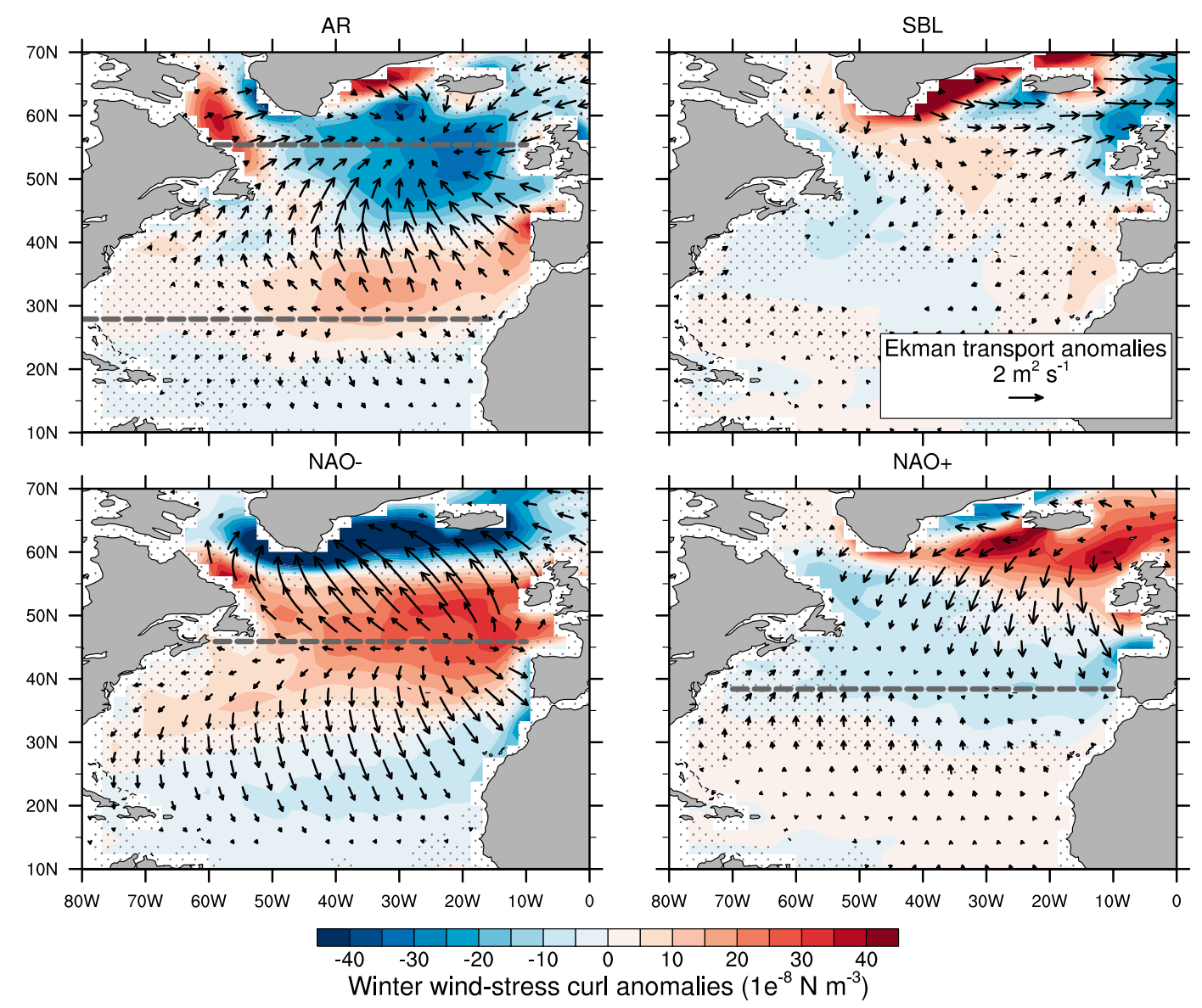

FIG. 1. NCEP-NCAR reanalysis composites of winter wind stress curl (color shading) and Ekman transport (black arrows) anomalies computed from daily anomalies occurring in each WR. Significance is assessed based on a Student's $t$ test at the 95\% level of confidence. Nonsignificant Ekman transport anomalies are omitted; nonsignificant wind stress curl anomalies are stippled. Dashed gray lines represent meridional Ekman transport anomaly convergence/divergence, determined from zonally averaged zonal winds.

variability of ocean circulation in the North Atlantic is likely to be impacted by the WRs.

\section{Experimental setup and mean state}

In this study, we use a regional North Atlantic configuration of the Nucleus for European Modelling of the Ocean (NEMO) model to assess the variability of the ocean circulation driven by the NAE WRs. In this section we describe the different model experiments, which are summarized in Table 1. A complete description of the model can be found in appendix A. The model is initialized from Levitus et al. (1998) climatology and spun up using DRAKKAR forcing set, version 4.3 (DFS4.3; Brodeau et al. 2010), over the period from 1958 to 2002. The reference experiment (REF) is run with identical forcing, starting from the end of the $45-\mathrm{yr}$ spinup. Figure $3 \mathrm{a}$ shows the mean barotropic streamfunction of REF. Subtropical and subpolar gyre intensities each reach about $35 \mathrm{~Sv}\left(1 \mathrm{~Sv} \equiv 10^{6} \mathrm{~m}^{3} \mathrm{~s}^{-1}\right)$, which compares well with other $z$-level OGCMs of similar resolution (Eden and Willebrand 2001). The Labrador Current transport is $32 \mathrm{~Sv}$, which is within the range of observations (Pickart and Spall 2007). However, the deep western boundary current is only $7 \mathrm{~Sv}$, slightly weak compared to the observational estimate of 12.4 Sv (Pickart and Spall 2007); a possible cause is the underrepresentation of the Greenland-Scotland Ridge overflows, which contribute to its intensity (Dickson and Brown 1994). The Gulf Stream separates too far south and the NAC is too zonal, which are well-known biases of coarse-resolution models (e.g., Smith et al. 2000; Treguier et al. 2005). The variability of the gyre transport compares well with other studies. The upward trend in subpolar gyre intensity from 1980 to 1995 (Treguier et al. 2005) and its decline from 1995 to 2000 (Häkkinen 

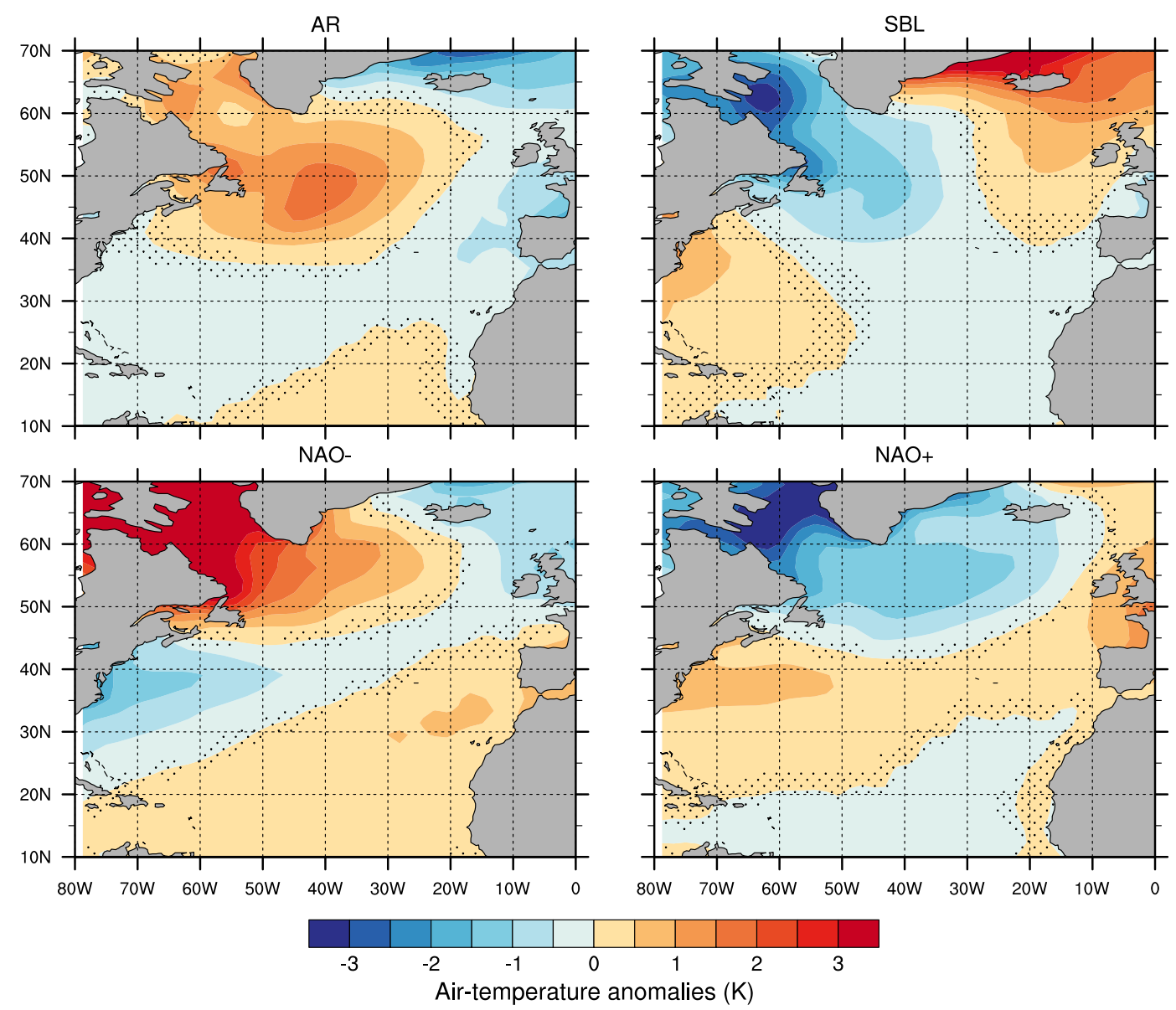

FIG. 2. As in Fig. 1, but for air temperature anomalies.

and Rhines 2004) are accurately reproduced. Variability in the subtropical gyre is additionally found to compare well with observations. For example, model sea level anomalies at Bermuda correlate with the tide gauge data of the Permanent Service for Mean Sea Level [used in Barrier et al. (2013)] at 0.63. The mean MOC for REF is shown in Fig. 3b. Its maximum, located at near $26^{\circ} \mathrm{N}$ and at a depth of $1000 \mathrm{~m}$, is approximately $17 \mathrm{~Sv}$. The North Atlantic Deep Water cell is slightly deeper and stronger than that reported by Biastoch et al. (2008). This is due to our different choice of forcing dataset, as shown by an unpublished comparison of two global NEMO simulations of the same horizontal resolution run with these different atmospheric forcings (J. M. Molines 2010, personal communication). The time series of maximum overturning at $46^{\circ} \mathrm{N}$ compares well with the results of Biastoch et al. (2008) and Böning et al. (2006), obtained from a higher-resolution model.

Wind and buoyancy forcing are connected through the turbulent fluxes of heat and evaporation, which depend on the surface wind speed (Large and Yeager 2004). To isolate the mechanical influence of interannually varying wind stress (i.e., via the momentum equation) from their influence on turbulent fluxes, a "wind only" model configuration is constructed as follows. Smoothed daily climatologies (two harmonics retained) of air temperature, specific humidity, and wind speed are computed using the 6-hourly forcing fields issued from DFS4.3. These climatologies are read and used by the model to compute the turbulent fluxes of evaporation and heat, while the wind stress is computed in the same way as in REF (i.e., using the 6-hourly wind fields issued from DFS4.3). The windonly reference experiment (WREF) is integrated from the end of the respective wind-only spinup run. The mean state in WREF compares well with REF, although the MOC and subpolar gyre are weaker in WREF, the latter particularly so in the Labrador Sea. Our methodology matches that of Biastoch et al. (2008), who use a global NEMO configuration at the same resolution. Their results suggest that the variability of the 
TABLE 1. List of the numerical experiments discussed in the text. All the experiments are run for 45 years (1958-2002).

\begin{tabular}{|c|c|c|}
\hline Configuration & Forcings & Description \\
\hline Spinup REF & DFS4.3. & $\begin{array}{l}\text { Reference spinup. Initialization from ocean at rest. } \\
\text { Tracer initialization from Levitus et al. (1998) } \\
\text { climatology. }\end{array}$ \\
\hline REF & Same as spinup REF. & Started from spinup REF. \\
\hline WR & $\begin{array}{l}\text { Idealized winter wind, temperature, and humidity. } \\
\text { DFS4.3 in summer. Climatological radiative fluxes, } \\
\text { precipitation, and snow. }\end{array}$ & Started from spinup REF. \\
\hline Spinup WREF & $\begin{array}{l}\text { DFS4.3 winds and climatological temperature, humidity, } \\
\text { radiative fluxes, precipitation, and snow. }\end{array}$ & $\begin{array}{l}\text { Wind-only spinup. Initialization from ocean at rest. } \\
\text { Tracer initialization from Levitus } \\
\text { et al. (1998) climatology. }\end{array}$ \\
\hline WREF & Same as spinup WREF. & Started from spinup WREF. \\
\hline WWR & $\begin{array}{l}\text { Identical to spinup WREF except for the winds, which } \\
\text { are identical to WR. }\end{array}$ & Started from spinup WREF. \\
\hline
\end{tabular}

MOC can be interpreted as the linear sum of winddriven interannual variability and buoyancy-driven decadal variability.

We have also built a barotropic configuration of the regional model that uses a single vertical level and that is only forced by the winds. In this configuration, salinity and temperature are constant in time and uniform in space (horizontally and vertically). Hence, the joint effect of baroclinicity and relief (JEBAR) term is neglected. The wind stress has been computed assuming a constant drag coefficient of $1.5 \times 10^{-3}$. This simple configuration permits reproducing the linear dynamics of ocean circulation-namely, the Sverdrup balance-as will be shown shortly.

\section{Oceanic fast response to recurrent winter weather regime conditions}

In this section, the immediate response of the ocean to recurrent weather regime conditions throughout monthly time scales is analyzed as follows. Monthly occurrences of AR are computed as the number of days, in each DJFM month over the period 1958-2002, that belongs to AR. The months that are characterized by extreme AR conditions (in a temporal sense)-defined as the months for which the monthly occurrences exceed the mean by 1.5 standard deviations-are sought for. Monthly anomalies of barotropic and overturning streamfunctions issued from REF (computed by removing the seasonal cycle) are then averaged over these extreme AR months, hence giving a picture of monthly circulation anomalies associated with AR (Figs. 4a,b). This methodology is then repeated for the other three regimes. The monthly composites of modeled wind stress curl anomalies, computed using this method, compare well with the daily composites of Fig. 1 (not shown), hence validating this methodology.
The extreme AR events are characterized by anomalies that project well onto the mean position of the gyres with a polarity that implies a weakening of the horizontal circulation (Fig. 4a). For extreme $\mathrm{NAO}^{-}$ conditions (Fig. 4e), negative anomalies are centered at near $45^{\circ} \mathrm{N}$, while south of $30^{\circ} \mathrm{N}$ anomalies are positive. Extreme $\mathrm{NAO}^{+}$conditions show slightly weaker anomalies of opposite polarity with respect to $\mathrm{NAO}^{-}$ events and centered at near $40^{\circ} \mathrm{N}$ (Fig. $4 \mathrm{~g}$ ). This is $5^{\circ}$ farther south of the $\mathrm{NAO}^{-}$anomalies due to a southward shift of the wind stress curl anomalies (Fig. 1). Both NAO composites share the same splitting of the altered circulation into two branches, one recirculating southeastward and the other one shifting northward toward the center of the subpolar gyre, even though these anomalies are reduced for $\mathrm{NAO}^{+}$. The two NAO patterns are consistent with the intergyre gyre pattern (Marshall et al. 2001) and can be interpreted as the signature of meridional shifts of the gyres due to NAOinduced north-south shifts of the position of the wind stress curl. One can notice in Fig. 4 the strong control of topography on the shape of the barotropic streamfunction anomalies, especially in the vicinity of the mid-Atlantic Ridge.

These results are likely due to topographic Sverdrup balance (Koblinsky 1990; Vivier et al. 1999), consistent with Eden and Willebrand (2001). To investigate this hypothesis, additional numerical experiments have been performed using the barotropic configuration of the model. The model is separately forced with constant wind anomaly composites that correspond to each WR (excluding SBL, which induces no significant ocean response; Fig. 4b). Two simulations have been run for 4 years, when the equilibrium is reached: one in which the model bathymetry is the same as in REF and a second one in which the bathymetry is flat (3000 $\mathrm{m}$ everywhere except on land). 

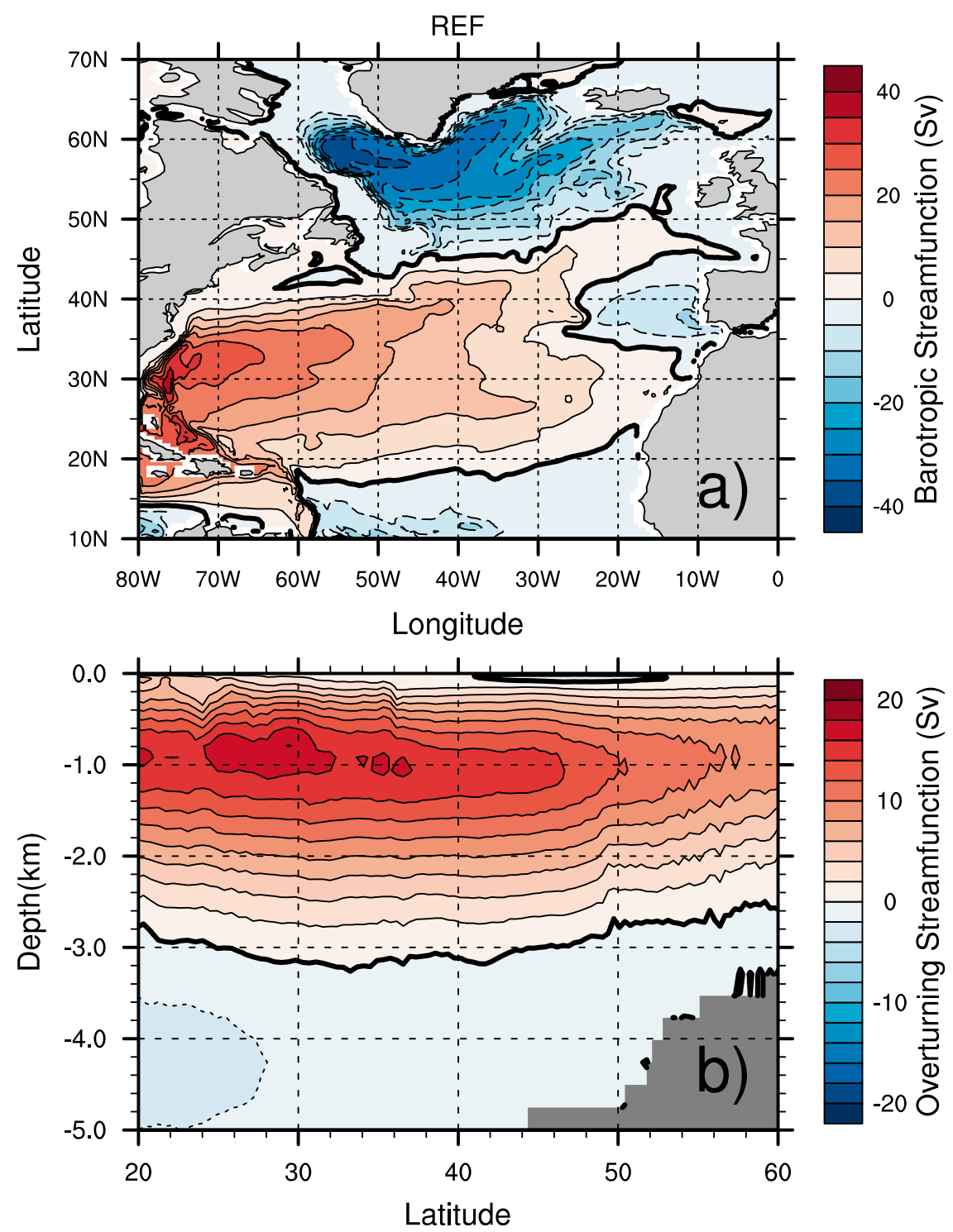

FIG. 3. Mean circulation in the REF experiment averaged over 45 years: (a) barotropic (contour interval: $5 \mathrm{~Sv}$ ) and (b) meridional overturning (contour interval: $2 \mathrm{~Sv}$ ) streamfunctions.

The results are shown in Fig. 5, averaged over the last year of integration. With the REF bathymetry, the barotropic configuration reproduces very well the patterns of Fig. 4. With the idealized bathymetry, stronger and more zonally elongated circulations are obtained (Figs. 5b,e,h), which are consistent with classical Sverdrup theory (Figs. 5c,f,i) and thereby confirm that the gyre anomalies of Fig. 4 are due to topographic Sverdrup balance, in agreement with Eden and Willebrand (2001).

However, the "instantaneous oceanic barotropic response" of Eden and Willebrand (2001) (their Fig. 8a) does not seem to be as constrained by the topography as indicated by the patterns in Fig. 4. This difference arises from the different time scales of interest. While we discuss monthly anomalies, Eden and Willebrand (2001) discuss yearly anomalies. We have thus computed the correlations at 0 lag between the yearly gyre anomalies (computed as the average from December to November to keep the continuity of winter months) and the winter sum of daily WR occurrences (winter occurrences). Each time series has been detrended prior to calculating the correlations. We notice a clear correspondence between the monthly gyre composites and the correlation patterns (Fig. 6), confirming that the signature of the barotropic, wind-driven response of ocean circulation to WRs occurs 

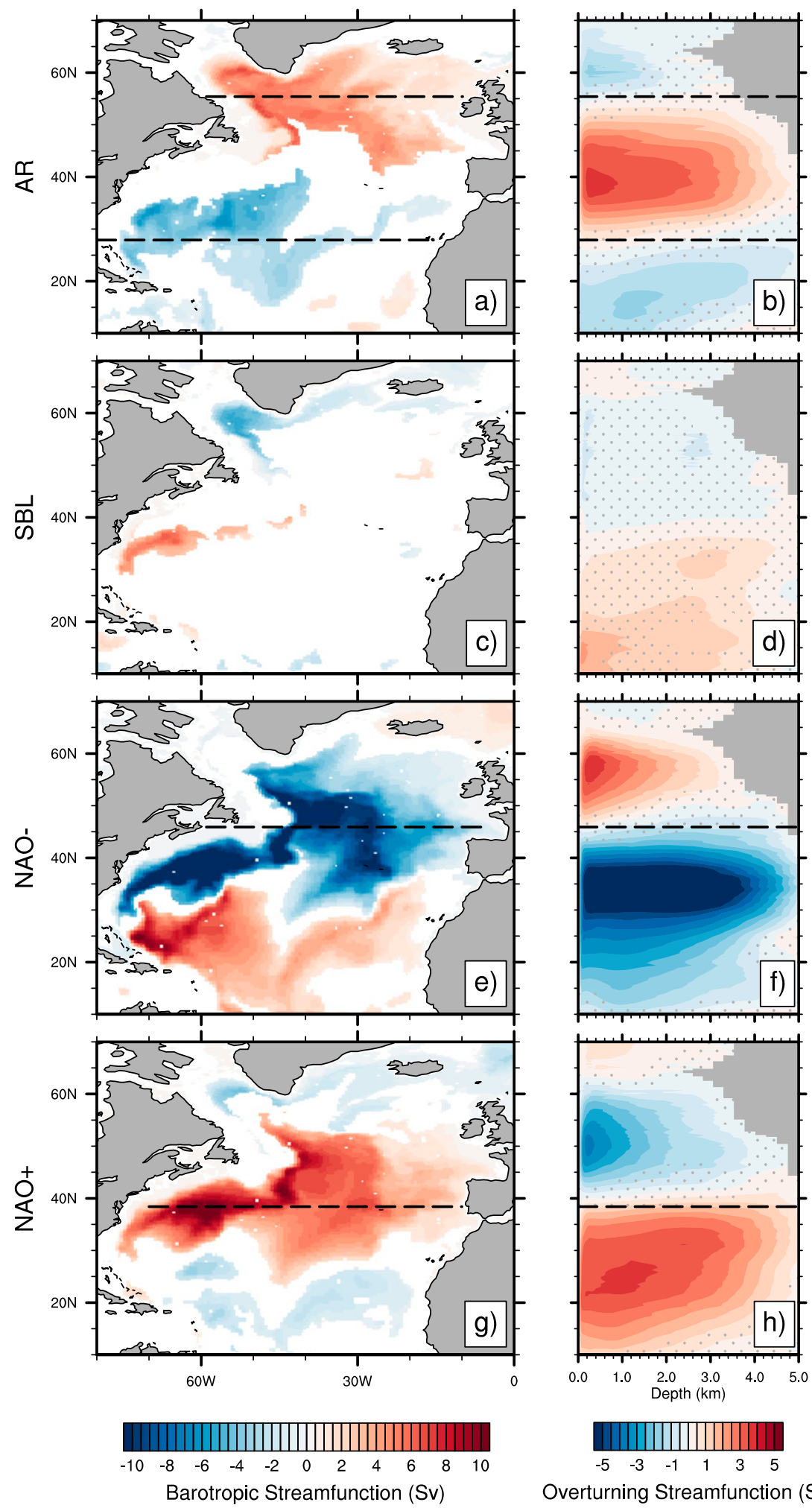

FIG. 4. Monthly composites of (a),(c),(e),(g) barotropic and (b),(d),(f),(h) overturning streamfunction anomalies issued from REF (see text for details). Nonsignificant values (Student's $t$ test at the 95\% level of confidence) are omitted (left) and stippled (right). Dashed black lines represent meridional Ekman transport anomalies convergence/divergence, determined from zonally averaged zonal winds. 

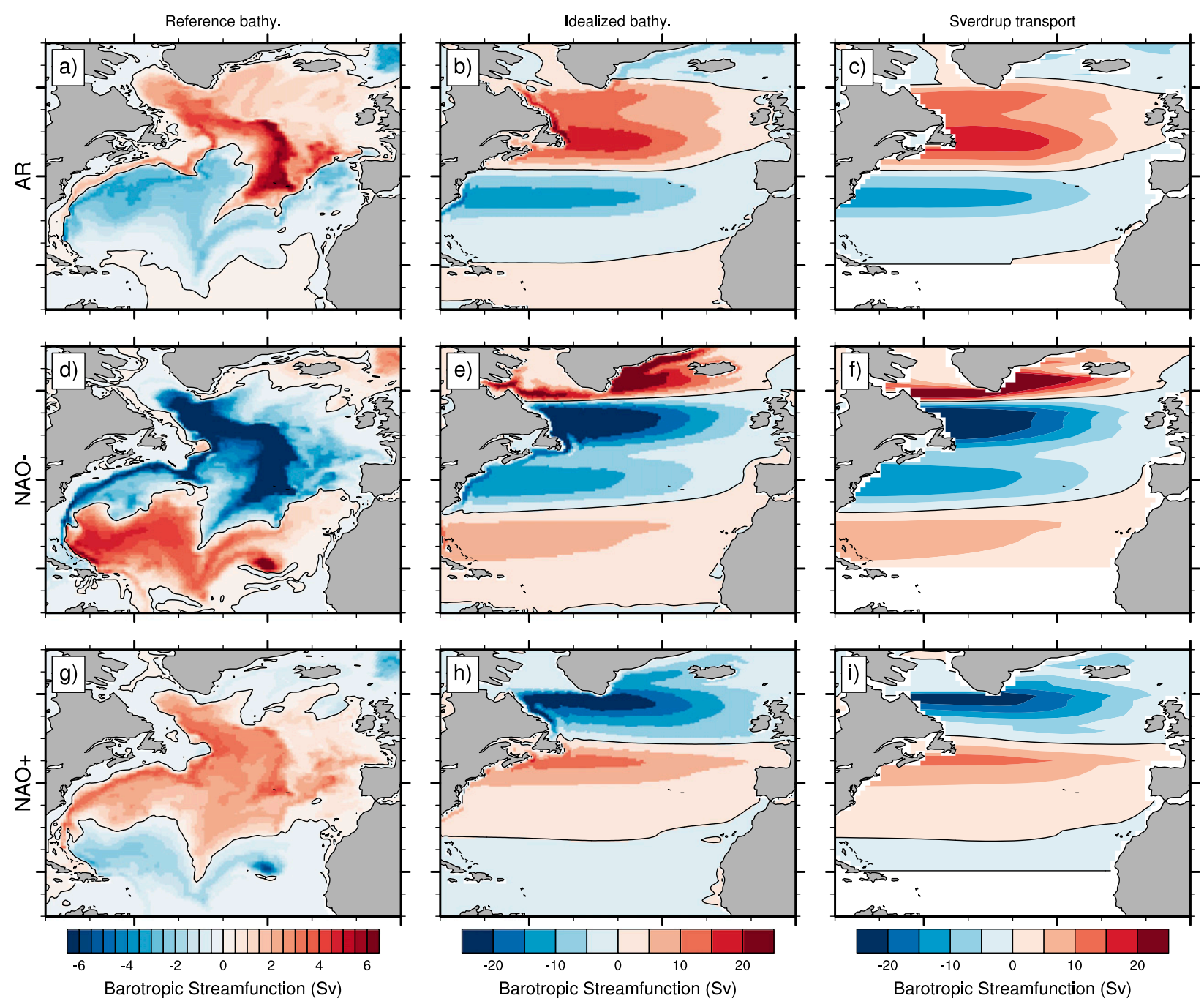

FIG. 5. Barotropic streamfunction averaged over the fourth year of the (a),(b),(d),(e),(g),(h) idealized barotropic experiments for reference (left) and idealized (middle) bathymetry (3000 m everywhere). (c),(f),(i) Classical Sverdrup theory.

within a year. However, the influence of topography is no longer obvious in the yearly correlations, indicating that the barotropic mode has been modified by the baroclinic ones (Anderson and Killworth 1977).

We now analyze the overturning streamfunction anomaly composites for extreme WR occurrences (Figs. $4 \mathrm{~b}, \mathrm{~d}, \mathrm{f}, \mathrm{h})$. While no significant responses are again found for SBL, significant anomalies extend from the surface to the bottom for the remaining three WRs. The AR composite shows a tripolar pattern, with positive anomalies between $30^{\circ}$ and $55^{\circ} \mathrm{N}$ and negative anomalies elsewhere. The $\mathrm{NAO}^{-}$composite shows a dipolar pattern with positive anomalies north of $45^{\circ} \mathrm{N}$ and negative anomalies in the south. The $\mathrm{NAO}^{+}$composite is comparable to the $\mathrm{NAO}^{-}$pattern but is opposite in sign and southward shifted. The anomalies are, in each case, located between the latitudes of convergence/divergence of meridional Ekman transport anomalies (dashed lines in Fig. 4) and are thus the signature of a near-surface flow driven by Ekman transport anomalies, compensated by a depth-independent flow (Jayne and Marotzke 2001; Köhl and Stammer 2008). Hence, these patterns reflect changes in volume transport rather than changes in water mass transformation. Comparable patterns are obtained from correlations between yearly MOC anomalies and the winter occurrences except north of $45^{\circ} \mathrm{N}$, where the significant correlations are restricted to the surface and at depth, which we fail to explain.

\section{Transient ocean response to winter regime conditions}

In the previous section, we have shown that the fast response of ocean horizontal/meridional circulation to 

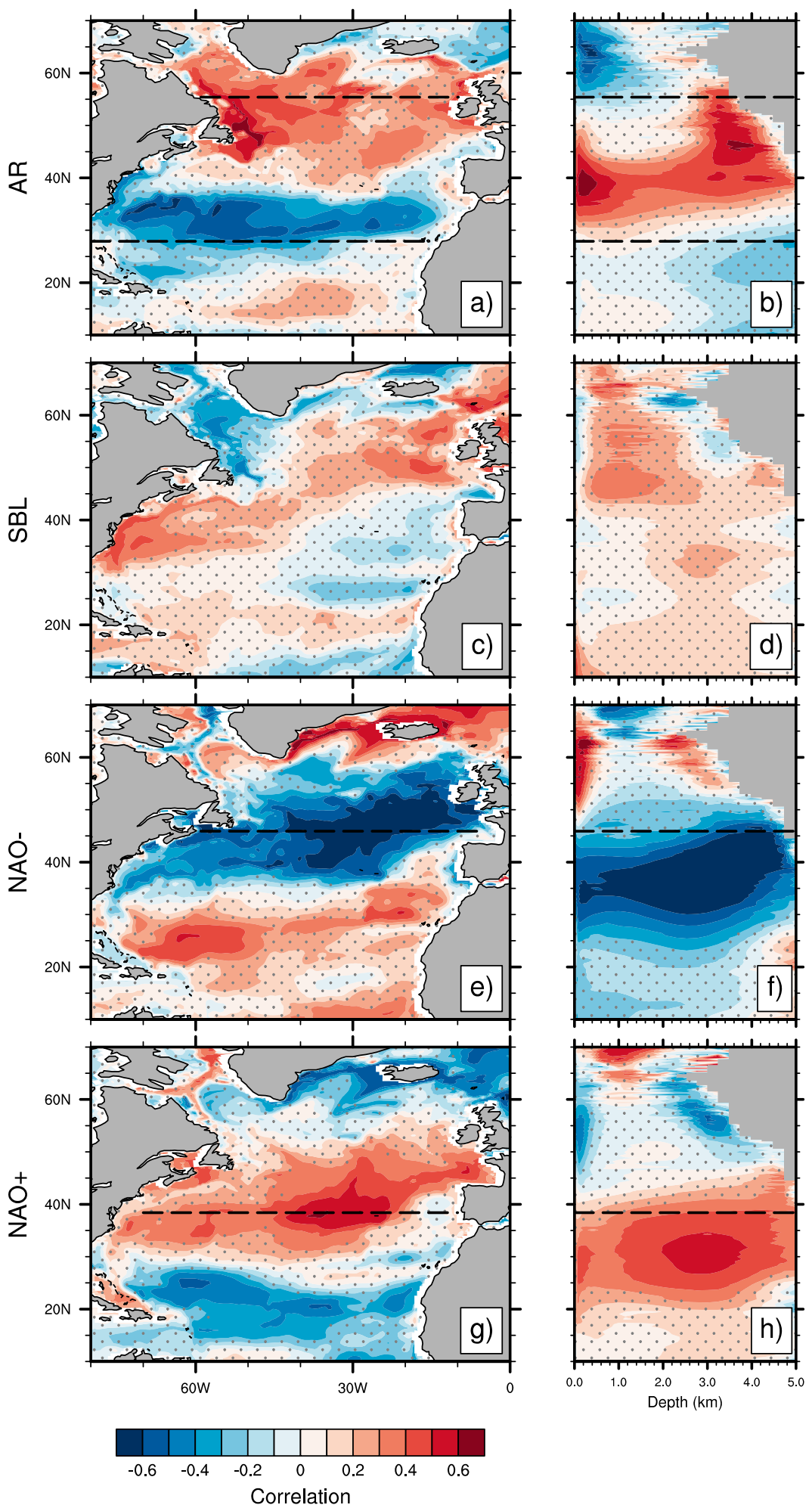

FIG. 6. Correlations of 0 lag between yearly averaged (a),(c),(e),(g) barotropic and (b),(d),(f),(h)overturning streamfunction anomalies issued from REF and the winter WR occurrences. Nonsignificant values (Student's $t$ test at 95\%) are stippled. Dashed black lines represent meridional Ekman transport anomalies convergence/divergence, determined from zonally averaged zonal winds. 
TABLE 2. Number of regime occurrences during the winters characterized by strongly positive EOF-derived NAO index. Boldface characters indicate the winters for which the percentage of $\mathrm{NAO}^{+}$days exceeds $50 \%$.

\begin{tabular}{rrrrrc}
\hline Year & AR & SBL & NAO $^{-}$ & NAO $^{+}$ & $\%$ NAO $^{+}$ \\
\hline 1983 & 45 & 24 & 4 & 48 & 39.7 \\
$\mathbf{1 9 8 9}$ & $\mathbf{2 1}$ & $\mathbf{3 3}$ & $\mathbf{1}$ & $\mathbf{6 6}$ & $\mathbf{5 4 . 5}$ \\
$\mathbf{1 9 9 0}$ & $\mathbf{9}$ & $\mathbf{2 7}$ & $\mathbf{1 5}$ & $\mathbf{7 0}$ & $\mathbf{5 7 . 9}$ \\
1992 & 28 & 51 & 5 & 38 & 31.1 \\
1994 & 19 & 21 & 21 & 60 & 49.6 \\
$\mathbf{1 9 9 5}$ & $\mathbf{2 3}$ & $\mathbf{2 1}$ & $\mathbf{8}$ & $\mathbf{6 9}$ & $\mathbf{5 7 . 0}$ \\
2000 & 54 & 14 & 5 & 49 & 40.2 \\
\hline
\end{tabular}

WRs is mostly driven by linear dynamics (Sverdrup and Ekman). How does the ocean adjust to persistent weather regime conditions on decadal time scales? This question has been addressed many times for the NAO using numerical experiments with idealized forcings that represent either strongly positive or strongly negative NAO conditions (e.g., Eden and Willebrand 2001; Lohmann et al. 2009; Zhu and Demirov 2011). To reconstruct such forcing conditions, the usual method is to add the observed daily variability of the forcing to idealized (NAO like) monthly forcing, which can either be the composite monthly anomalies computed over years of strong NAO conditions (Lohmann et al. 2009; Zhu and Demirov 2011) or the regression of monthly anomalies onto the monthly NAO index (Visbeck et al. 1998; Eden and Willebrand 2001). A major drawback of these methods is that the NAO index is polluted by (i) large-scale anomalous circulations that may not be representative of the NAO meridional seesaw pressure pattern and (ii) synoptic storms that pass either over Iceland or the Azores. This thereby gives artificial weight to one of the NAO fixed points. Put differently, in the context of the WR paradigm, a year of positive NAO index may include a significant number of days that belong to the three other weather regimes. To illustrate this, Table 2 provides the winter occurrences of each regime during the years usually employed in the $\mathrm{NAO}^{+}$composite calculation (Lohmann et al. 2009; Zhu and Demirov 2011). During these 7 years, only three of them $(1989,1990$, and 1995) are dominated by the $\mathrm{NAO}^{+}$. For example, year 1992 is dominated by SBL and has only $31 \%$ of $\mathrm{NAO}^{+}$days. The traditional NAO index is thus strongly positive in 1992 because $\mathrm{NAO}^{-}$episodes almost never occurred during that winter. Hence, we suggest that the use of monthly indexes may not be the best choice for estimating the sensitivity of ocean circulation to specific atmospheric conditions.
As an alternative, we propose a new method based on WRs that constructs idealized surface forcings that we believe better capture the true nature of the NAE atmospheric circulation and their impacts upon the ocean. This method is significantly different from those described above, as it is done on daily criteria instead of monthly means, as detailed below for the $\mathrm{NAO}^{+}$. Idealized forcings are generated using only the winter months (December-March). As an example, we here describe the construction of the 1 December forcings. One $\mathrm{NAO}^{+}$event is randomly selected from the 19582002 pool of WR NAO ${ }^{+}$days. This selected $\mathrm{NAO}^{+}$ event may correspond, for instance, to the one that began on 24 January 1989 and lasted 4 days. The anomalous surface forcing fields (computed as done in section 2) of this 4-day period are then added to the 1-4 December daily climatology. The same methodology is repeated for 5 December. Let us say that a strong $\mathrm{NAO}^{+}$ event lasting 13 days is now randomly selected. The 13-day sequence is used to construct forcings from 5 to 18 December by adding the anomalous $\mathrm{NAO}^{+}$conditions to the daily climatology. This process is continued up until 31 March. The same procedure is then repeated to construct $45 \mathrm{NAO}^{+}$winters that are then used to force the model.

This technique allows us to better isolate the atmospheric circulation of interest and enables us to better retain the statistical characteristics of the circulation. It is important to note that $\mathrm{NAO}^{+}$conditions refer to a range of $\mathrm{NAO}^{+}$events of different strength, duration, and spatial characteristics. These statistics can be assessed by the so-called distance to the WR centroids, which we use to verify that our method allows us to accurately sample both the distribution of distances that correspond to $\mathrm{NAO}^{+}$conditions and the variety of duration of the $\mathrm{NAO}^{+}$events. Accordingly, we reproduce fairly well the forcing statistics of the $\mathrm{NAO}^{+}$ events, as shown in appendix B. The same technique is applied to construct forcing fields for all four regimes. Note that only winter days are rebuilt, while DFS4.3 is still used for the other seasons. Moreover, we have chosen to use climatologies for radiative fluxes, snow, and precipitation in the idealized forcing datasets that have been applied in the sensitivity experiments. We have verified that this choice has no effect on gyre or overturning circulation variability by running an additional experiment that is identical to REF except that it uses climatological snow, precipitation, and radiative fluxes (not shown).

A set of four experiments has been performed (one for each regime) in which the model was integrated with the idealized forcings for 45 years, initiated following the same spinup as for REF. These experiments will be 

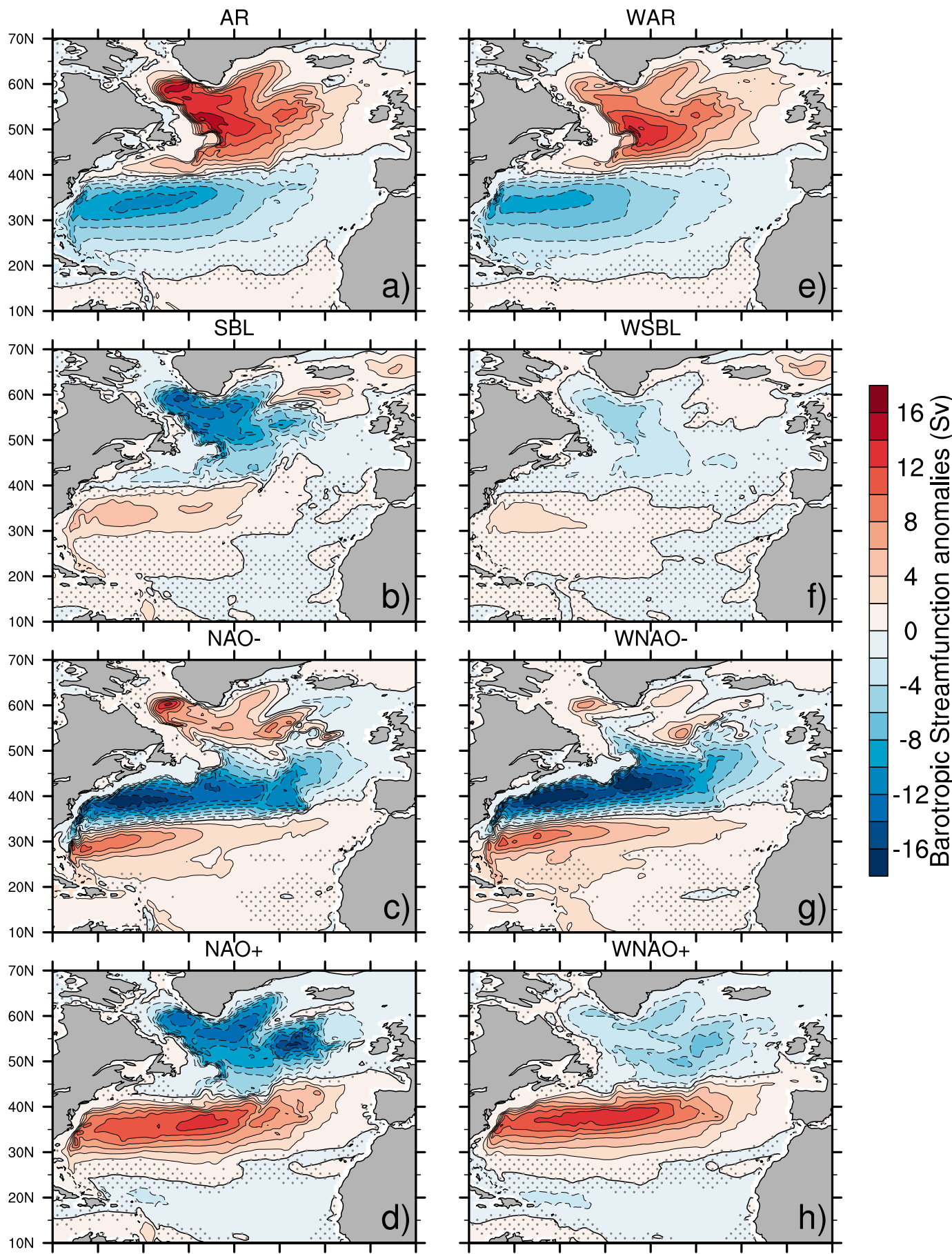

FIG. 7. Differences between the barotropic streamfunction of the idealized WR or WWR experiments averaged over the last 10 years and the barotropic streamfunction of their respective reference experiments (REF or WREF) averaged over 45 years. Thick black lines represent the 0 contour. Stippled contours are nonsignificant values based on a Student's $t$ test at the $95 \%$ level.

referred to as $\mathrm{AR}, \mathrm{SBL}, \mathrm{NAO}^{-}$, and $\mathrm{NAO}^{+}$. Another set of four idealized experiments have also been performed to isolate the influence of the wind forcing $W$. These experiments, referred to as WAR, WSBL,
$\mathrm{WNAO}^{-}$, and $\mathrm{WNAO}^{+}$, respectively, have been integrated starting from the WREF spinup and forced using only the wind component of each WR. The numerical experiments are summarized in Table 1. 


\section{a. Gyre circulation}

The difference between the barotropic streamfunction averaged over the last 10 years of the WR sensitivity experiments and the reference barotropic streamfunction (averaged over the full 45 years of the REF experiment; see Fig. 3a) is displayed in Fig. 7. AR and $\mathrm{NAO}^{+}$(Figs. 7a,d) exhibit anomalies that project well onto the mean circulation and thus depict a change in the intensity of the circulation (about $15 \mathrm{~Sv}$ ). The circulation is weaker for AR, especially on the western side of the basin, and strengthened for $\mathrm{NAO}^{+}$, especially in the central part of the subtropical gyre and eastern part of the subpolar gyre. SBL anomalies (Fig. 7b) are similarly strengthened in the western part of the subpolar gyre, while the subtropical gyre is not altered. The $\mathrm{NAO}^{-}$ anomalies (Fig. 7c) display a tripolar anomaly pattern, consistent with a southward shift of the gyres (the intergyre gyre; Marshall et al.2001), and a strengthening of the circulation in the northern limb of the subpolar gyre, with maximum anomalies in the Labrador Sea.

Similar comparisons are performed for the wind-only experiments (Figs. 7e-h). WR and WWR anomalies show very comparable patterns in the subtropics (south of $45^{\circ} \mathrm{N}$ ). Accordingly, the response of the subtropical gyre to persistent WRs is interpreted to be mostly driven by the baroclinic adjustment of the gyre to anomalous wind stress curl, via the westward propagation of planetary waves (Cabanes et al. 2006; Hong et al. 2000; Barrier et al. 2013). In the subpolar gyre, the ocean response is regime dependent. AR and WAR show very comparable anomalies, indicating that the adjustment of the subpolar gyre to persistent AR is also mostly wind driven, although the contribution of buoyancy forcing cannot be neglected. This extends to the subpolar gyre the conclusions found in Barrier et al. (2013) for the subtropical gyre, and is consistent with the gyre mode of Häkkinen et al. (2011a). Similar conclusions cannot be drawn for the other three regimes. Indeed, the strength of the subpolar gyre is barely affected in the WSBL, $\mathrm{WNAO}^{-}$, and $\mathrm{WNAO}^{+}$experiments. Following Biastoch et al. (2008), who linearly decompose the circulation anomalies into wind- and buoyancy-driven components, the difference between the WR and WWR experiments would correspond to the signal being driven by buoyancy fluxes. Accordingly, the strengthening of the subpolar gyre in $\mathrm{SBL}$ and $\mathrm{NAO}^{+}$and its slackening in $\mathrm{NAO}^{-}$are interpreted as being mostly driven by baroclinic adjustment to persistent heat flux anomalies. Interestingly, the WWR spatial anomalies are very similar to the correlation patterns of Fig. 6. This further confirms that these correlation patterns are a signature of the baroclinic adjustment following the perturbation by the wind forcing.
Figure 8 shows the time evolution of the maximum gyre transport in the four WR and WWR experiments. The subtropical gyre adjustment is achieved in 6-8 years, consistent with the time scales of baroclinic adjustment to wind stress curl. It is worth noting that only the AR regime leads to a slackened subtropical gyre, consistent with Häkkinen et al. (2011b), while the three others tend to intensify it. Despite differences in the mean states that are controlled by the winter forcing, $\mathrm{REF}, \mathrm{SBL}$, and $\mathrm{NAO}^{+}$share very similar interannual variability. This is presumably because during SBL and $\mathrm{NAO}^{+}$days, the variance of winter wind stress curl is weaker (not shown), hence less likely to influence the interannual variability of the subtropical gyre. As a consequence, the interannual variability of the subtropical gyre in SBL and $\mathrm{NAO}^{+}$is dominated by the atmospheric forcing of the other seasons, especially spring and fall (April, May, October, and November), during which both summertime and wintertime dynamics statistically occur (Cassou et al. 2011, their Fig. 12).

The subpolar gyre adjustment is achieved in approximately 10-12 years. The longer adjustment time scale in the subpolar gyre compared to the subtropical gyre presumably reflects (i) that the subpolar gyre is primarily driven by heat flux rather than wind stress curl anomalies (cf. Eden and Willebrand 2001; Eden and Jung 2001) and (ii) that the speed of Rossby waves decreases with increasing latitude. In the $\mathrm{NAO}^{-}$and $\mathrm{WNAO}^{-}$idealized experiments, the subpolar gyre has not stabilized after 45 years, presumably reflecting a positive feedback via anomalous advection of warm subtropical water in the northeastern North Atlantic that spreads throughout the subpolar gyre and further decreases its strength (Sarafanov et al. 2008; Herbaut and Houssais 2009).

\section{b. Overturning circulation}

We now consider the difference between the overturning streamfunction averaged over the last 10 years of the WR experiments and the reference overturning streamfunction (the average over the 45 years of the REF experiment; see Fig. 3b). For persistent AR and $\mathrm{NAO}^{-}$conditions (Figs. 9a,c), the MOC experiences a large-scale weakening, while persistent $\mathrm{SBL}$ and $\mathrm{NAO}^{+}$ conditions induce a large-scale strengthening of the MOC (Figs. 9b,d). The anomalies are stronger for $\mathrm{NAO}^{-}$and $\mathrm{NAO}^{+}(4 \mathrm{~Sv})$; $\mathrm{SBL}$ anomalies reach $3 \mathrm{~Sv}$, while AR ones are weaker still at $2 \mathrm{~Sv}$. On top of the large-scale changes, small overturning circulation changes induced by Ekman transport anomalies are visible from 0 to approximately $500 \mathrm{~m}$.

In WAR, $\mathrm{WNAO}^{-}$, and $\mathrm{WNAO}^{+}$(Figs. 9e,g,h), the anomalies are of the same sign but with much smaller 

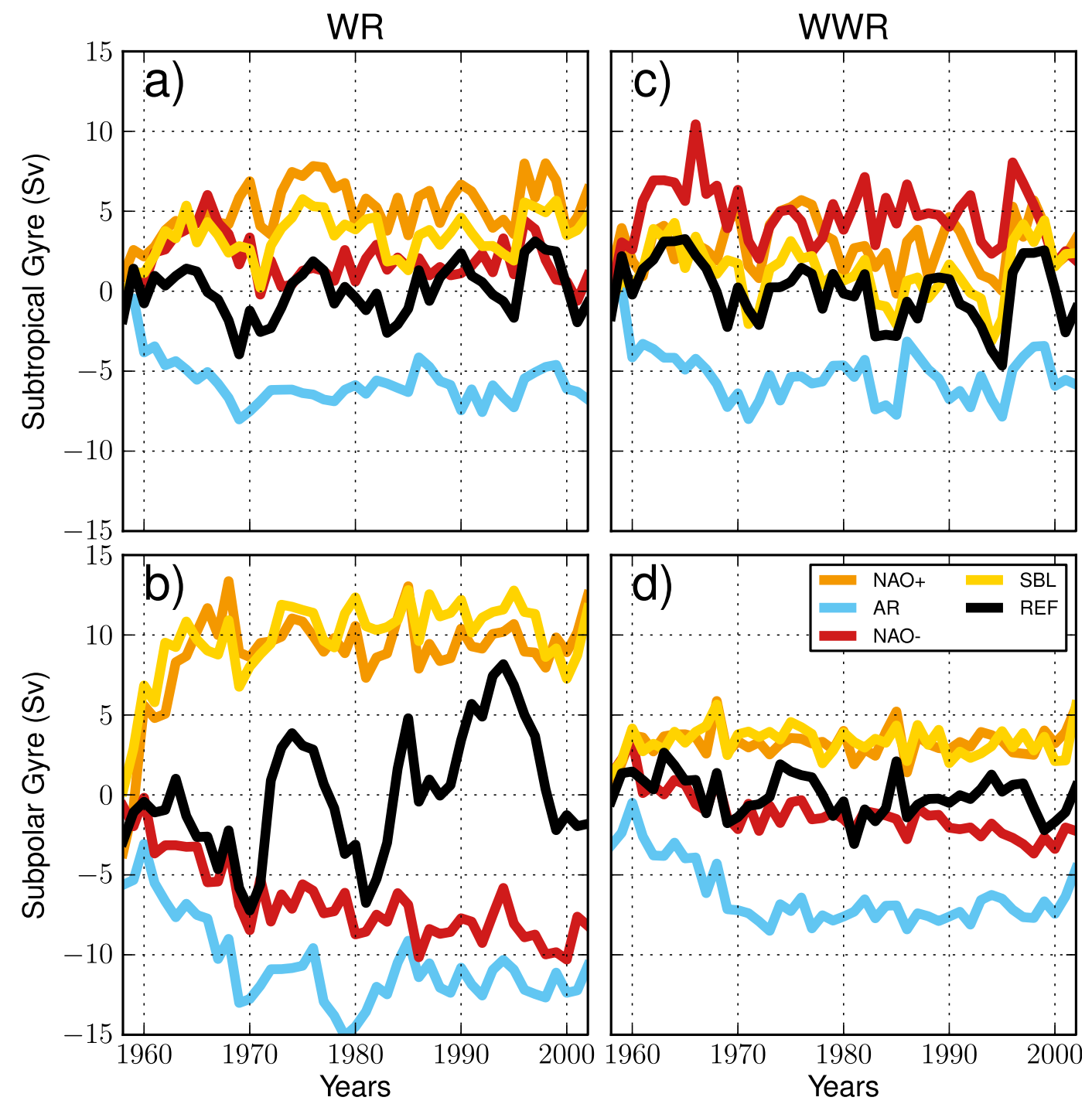

FIG. 8. Max strength of the (a),(c) subtropical and (b),(d) subpolar gyres in the sensitivity experiments (colored lines). In each panel, the means of the reference experiments [REF (left) and WREF (right), black lines] have been removed.

amplitude. In WSBL, however, the anomalies have the opposite sign and are almost zero (Fig. 9f). Because these differ from the immediate MOC response to extreme WR conditions (both on monthly and yearly time scales, Figs. 4, 6), the MOC patterns in WAR, $\mathrm{WNAO}^{-}$, and $\mathrm{WNAO}^{+}$likely reflect the impact of the adiabatic (wind driven) changes in gyre circulation. Because the MOC anomalies are much smaller in the wind-only experiments (i.e., WAR vs AR, $\mathrm{WNAO}^{-}$vs $\mathrm{NAO}^{-}$, and $\mathrm{WNAO}^{+}$vs $\mathrm{NAO}^{+}$), the MOC adjustment to persistent WRs is clearly demonstrated to be mostly due to heat flux anomalies. Nevertheless, the fact that the structure and sign of the anomalies are similar within each pair of sensitivity experiments suggests that the adiabatic gyre adjustment contributes to the MOC adjustment. We speculate that this effect is actually dampened by the absence of interannual heat flux anomalies in the windonly experiments because the stronger stratification of the subpolar gyre in WREF compared to REF may limit the gyres' influence on MOC.

We find that the MOC anomalies for persistent regime conditions are mostly driven by changes in Labrador Sea deep convection associated with heat flux anomalies: $\mathrm{AR}$ and $\mathrm{NAO}^{-}$show an anomalous heat gain that reduces convection, while $\mathrm{SBL}$ and $\mathrm{NAO}^{+}$are characterized by a strong heat loss that enhances deep convection. This is further confirmed by the mean late winter (January-March) mixed layer depth maximum in 

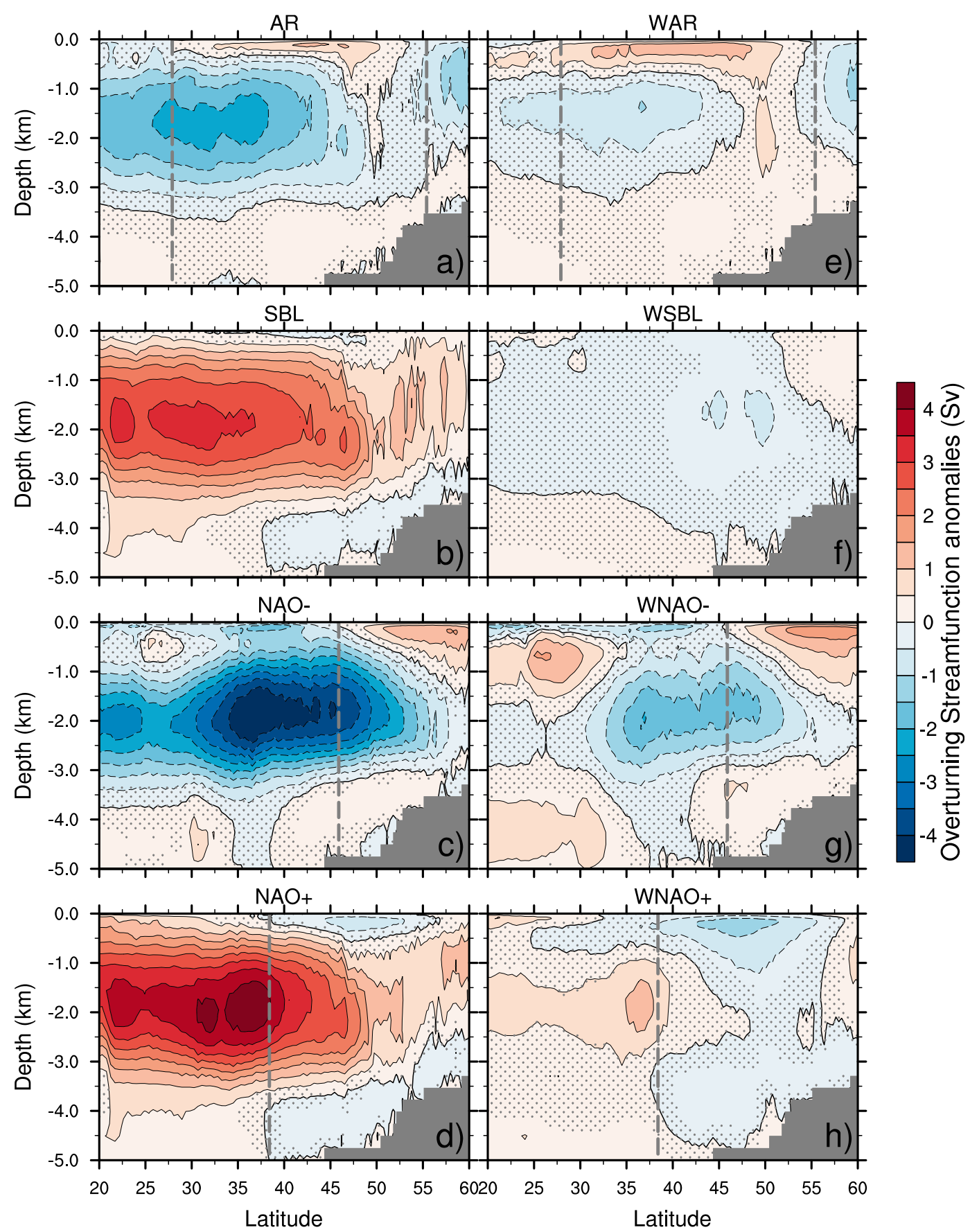

FIG. 9. As in Fig. 7, but for the overturning streamfunction. Dashed gray lines represent meridional Ekman transport anomalies convergence/divergence, determined from zonally averaged zonal winds.

the Labrador Sea, which is $1000 \mathrm{~m}$ shallower in AR and $\mathrm{NAO}^{-}$than in REF, and $1000 \mathrm{~m}$ deeper in $\mathrm{NAO}^{+}$and SBL than in REF (not shown). Consistent with the studies of Eden and Greatbatch (2003), Böning et al. (2006), and Biastoch et al. (2008), enhanced deep convection precedes positive MOC anomalies at latitudes north of $45^{\circ} \mathrm{N}$ by $0-2$ years. These anomalies are then rapidly (within a year) propagated southward, presumably by fast boundary Kelvin waves, as discussed by Getzlaff et al. (2005) (and references therein).

Figure 10 shows the temporal adjustment of the MOC diagnosed from the maximum overturning at $46^{\circ} \mathrm{N}$ in the WR and WWR experiments. The strengthening of the MOC during persistent SBL and $\mathrm{NAO}^{+}$is achieved 

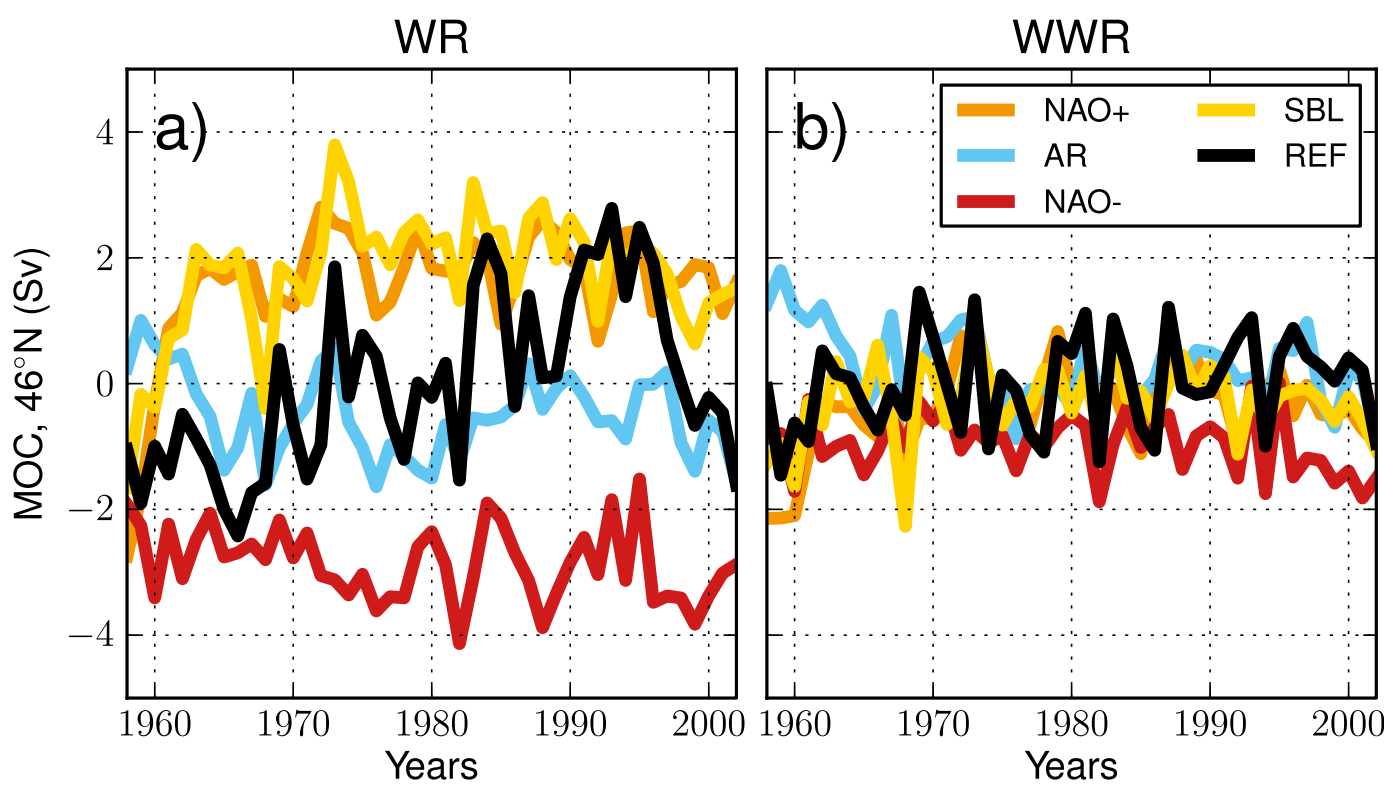

FIG. 10. As in Fig. 8, but for the max overturning streamfunction at $46^{\circ} \mathrm{N}$.

within $12-15$ years. In contrast to the horizontal circulation, it is worth emphasizing that MOC indices in our sensitivity experiments are much less correlated at interannual time scales. It can therefore be suggested that most of the changes in the MOC are controlled by winter conditions.

\section{Discussion}

In this study, we have assumed that NAE atmospheric winter dynamics can be partitioned into four WRs, a commonly accepted number based on simple statistical significance tests (Michelangi et al. 1995). The number of regimes remains subjective, however, because of the shortness of the observational datasets, the types of algorithm used for clustering, the choice of the null hypothesis used for assessing statistical robustness, etc. (Rust et al. 2010). As such, we have therefore repeated the present analyses when five regimes are retained instead of four. The fifth one resembles the opposite of $\mathrm{AR}$ and is characterized by a cyclonic anomaly located at the same latitude as the AR anticyclone but shifted eastward; we name this regime Atlantic low (AL). The gyre response to persistent AL mirrors the response to persistent $\mathrm{AR}$, as the wind stress curl anomalies are at the same latitude. MOC anomalies for persistent AL conditions show a pattern that resembles the AR one, but with smaller amplitudes. This is presumably because the AL eastward-shifted pattern displaces the wind and air temperature anomalies out of the Labrador Sea, hence preventing changes in deep water formation. As a consequence, MOC anomalies only reflect the contributions of Ekman transport anomalies and of the adiabatic spinup of the gyres. Both AL and AR project very well onto the EAP, but our results highlight that to understand the ocean response to atmospheric changes, it is of primary importance to account for the spatial asymmetry associated with the phases of the mode.

The analyses presented here have been carried out using a coarse-resolution regional model whose low computational demand allows us to perform several targeted integrations following a mechanistic approach. However, such a configuration has nonnegligible drawbacks. First, the choice of closed boundaries can lead to a misrepresentation of the mean state and variability of the MOC. Its interannual variability due to exchanges with the Arctic (Jungclaus et al. 2005) and changes in the overflows from the Nordic seas (Schweckendiek and Willebrand 2005; Danabasoglu et al. 2010) is indeed missing. To verify, however, that our regional model has some skill in reproducing the variability of the subpolar gyre and overturning circulation, we have compared our results with the global ocean-only simulation of NEMO described in Treguier et al. (2007). As shown in Fig. 11, although the two model configuration have different means, the interannual variability is very similar (correlations greater than 0.9). This gives us confidence that our results are robust despite the use of a regional model. Second, our coarse-resolution model does not resolve mesoscale eddies, which are parameterized following Gent and McWilliams (1990). As described in Deshayes et al. (2009), eddies play a major role in North Atlantic Deep Water formation and so our findings 

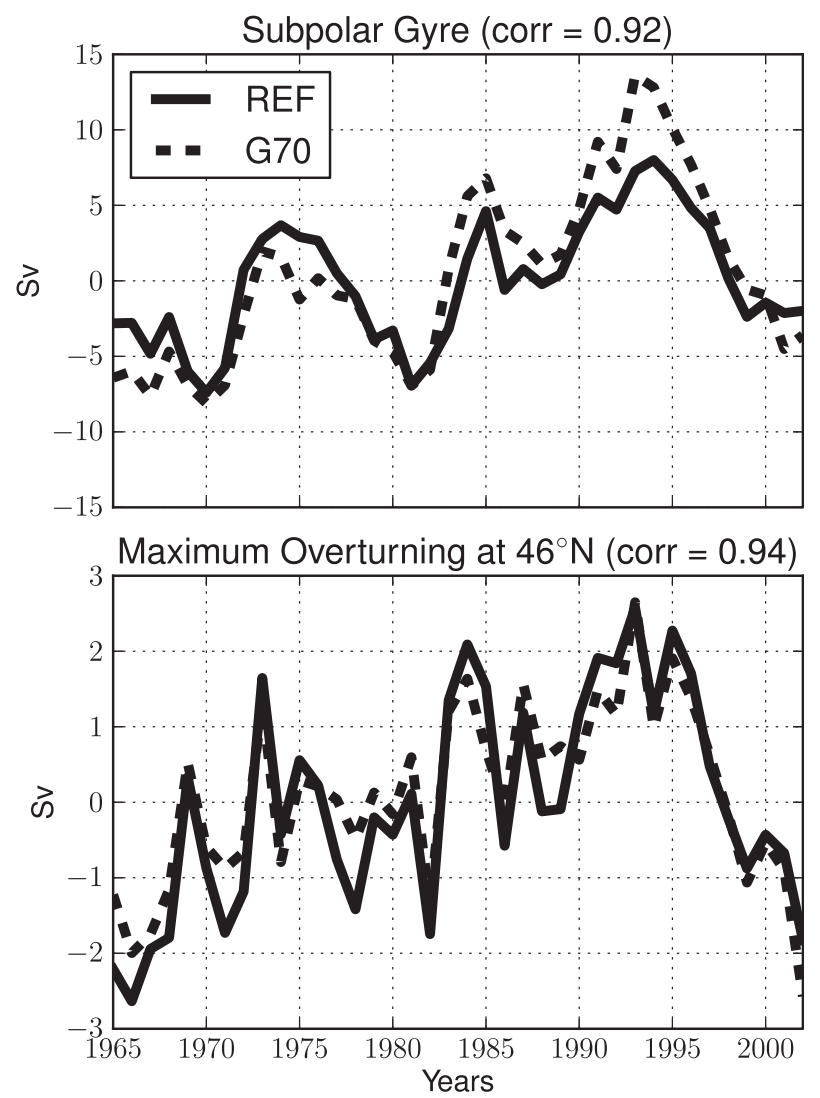

FIG. 11. Yearly averaged anomalies of subpolar gyre and overturning streamfunction strength for the regional model configuration used in this study (black lines) and the global NEMO simulation of Treguier et al. (2007). Correlations between the two models are indicated on top of the panels.

might be subjected to the misrepresentation of key associated physics. Eddies establish the time scales of integration of surface buoyancy forcing in the Labrador Sea, and their inclusion in ocean models significantly improves the representation of the ocean mean state, especially the Gulf Stream separation location and the NAC pathway (Smith et al. 2000; Treguier et al. 2005).

\section{Conclusions}

The North Atlantic/Europe atmospheric variability is usually partitioned into modes of variability, such as the North Atlantic Oscillation (NAO; Hurrell 1995) or the east Atlantic pattern (EAP; Barnston and Livezey 1987). This partition assumes that the modes are orthogonal and their phases spatially symmetric. In this study, we revisit the impact of atmospheric forcings upon the circulation of the North Atlantic Ocean by using weather regimes (WRs) instead of the more traditional approaches of isolating modes commonly found in the literature. WRs are defined as large-scale, recurrent, and quasi-stationary atmospheric patterns. Their use enables the spatial differences between the two NAO phases to be distinguished and Scandinavian blocking events to be isolated. Cassou et al. (2011) and Minvielle et al. (2011) have shown that WRs capture the interannual variability of the surface ocean forcing and are very useful for assessing the ocean response to atmospheric changes. As the variance of atmospheric forcings is greater in winter months (from December to March), with an accordingly larger impact on ocean circulation, only winter WRs are considered in this study. The four weather regimes are the so-called Atlantic Ridge (AR), Scandinavian blocking regime (SBL), and two NAO phases $\left(\mathrm{NAO}^{-}\right.$and $\mathrm{NAO}^{+}$).

We have investigated the imprints of the WRs on the horizontal and vertical North Atlantic Ocean dynamics using a series of numerical experiments performed with a regional, coarse-resolution ocean model. We have separated the fast oceanic response (with time scales from a month to a year) from the transient response (within decades) in our analysis. The former has been analyzed using statistical analyses (composites and correlations) of a historical experiment, while the latter has been analyzed using sensitivity experiments forced with idealized representations of each WR. The forcing datasets are constructed from the full distribution of observed WR events. In contrast to more traditional methods, we can verify that this novel approach captures the entire statistical distribution of the atmospheric circulation.

The fast response of the gyre circulation is found to be mostly wind driven and to be significant for $\mathrm{AR}, \mathrm{NAO}^{-}$, and $\mathrm{NAO}^{+}$but negligible for SBL. On a monthly basis, gyre anomalies are shown to be clearly constrained by the topography and are thus likely driven by topographic Sverdrup balance, which we confirm using a barotropic configuration of the model. As time goes on, the initial barotropic mode is modified by the baroclinic modes that eventually remove the influence of the topography (Anderson and Killworth 1977). The transient response of the subtropical gyre to WRs is an intensification for $\mathrm{NAO}^{+}$ but a weakening for $\mathrm{AR}$, in each case adjusting over a time scale of about 6-8 years. The gyre response for persistent $\mathrm{NAO}^{-}$consists of a southward shift of the subpolar front (the intergyre gyre; Marshall et al. 2001) due to the southward shift of wind stress curl in $\mathrm{NAO}^{-}$. No change occurs for SBL. Additional sensitivity experiments in which forcings were limited to the wind components were performed, which confirm that the changes in the subtropical gyre are primarily a response to wind forcing. At higher latitudes, weakening of the subpolar gyre is found during persistent AR conditions that are also mainly attributed to wind forcings though also in part to anomalous 
heat fluxes. In the case of persistent $\mathrm{SBL}$ and $\mathrm{NAO}^{+}$ conditions, the anomalous heat fluxes play a dominant role in driving changes in the subpolar gyre. Buoyancy fluxes also play a crucial role in the reduction of the circulation in the northern limb of the subpolar gyre during $\mathrm{NAO}^{-}$ conditions.

The fast response of the MOC is also found to be wind driven, simply reflecting an Ekman-induced surface flow that is compensated at depth (Jayne and Marotzke 2001). The transient response of the MOC to persistent WRs is characterized by a large-scale weakening during persistent $\mathrm{AR}$ and $\mathrm{NAO}^{-}$and a large-scale strengthening during persistent $\mathrm{SBL}$ and $\mathrm{NAO}^{+}$. These signals are driven by changes in deep water formation in the Labrador Sea that are driven by heat flux anomalies associated with the WRs. When only the influence of wind stress is considered, we obtain weak anomalies that are likely driven by the adiabatic spinup of the gyres. However, under such conditions, greater stratification in the subpolar gyre likely reduces the gyres' influence on the MOC. It then presumably leads to an underestimation of the influence of the adiabatic spinup of the gyres on the MOC transient response.

The strong contrast between the gyre responses to persistent $\mathrm{NAO}^{-}$and $\mathrm{NAO}^{+}$conditions illustrates the usefulness of the WR paradigm. Our study also highlights that atmospheric variability cannot be described solely by a single NAO index. By assuming so, one misses the important wind-driven contribution associated with $\mathrm{AR}$ and the buoyancy-driven contribution of SBL. Our study raises the question of whether the oceanic response to WRs is dependent on the oceanic mean state. Accordingly, sensitivity experiments are currently being carried out that use ocean states representative of the end of the twentyfirst century, when anthropogenic forcing is predicted to have substantially modified the three-dimensional North Atlantic Ocean's states and surface fluxes.

Acknowledgments. DFS4.3 forcings were provided by the DRAKKAR group. NCEP-NCAR reanalysis data were provided by NOAA/OAR/ESRL PSD, Boulder, Colorado, from its website (http://www.esrl.noaa.gov/psd/). Nicolas Barrier is supported by a doctoral grant from Université de Bretagne Occidentale, Ifremer, and Europôle Mer. Anne-Marie Treguier, Christophe Cassou, and Julie Deshayes acknowledge the support of CNRS. The numerical simulations were made using the CAPARMOR computing center at Ifremer (Brest, France) and the GENCI-IDRIS center (Orsay, France). The analysis and plots of this paper were performed with the NCAR Command Language (version 6.0.0, 2011), Boulder, Colorado (UCAR/NCAR/CISL/VETS, http://dx.doi.org/10.5065/ D6WD3XH5). The authors acknowledge the anonymous reviewers and the editor for their detailed and helpful comments. The authors also acknowledge Matthew Thomas for his comments and corrections and Alain Colin de Verdière for interesting discussions.

\section{APPENDIX A}

\section{Detailed Model Description}

The ocean model used in this study is the Nucleus for European Modelling of the Ocean (NEMO; Madec 2008), which is coupled with the Louvain-la-Neuve Sea Ice Model, version 2 (LIM2; Fichefet and Maqueda 1997). We use a regional North Atlantic configuration generated from the global ORCA05 version described by Biastoch et al. (2008) that is part of the model hierarchy of the DRAKKAR Group (http://www.drakkar-ocean.eu). The regional domain covers the North Atlantic from $20^{\circ} \mathrm{S}$ to $80^{\circ} \mathrm{N}$ and includes the Nordic seas and the western Mediterranean Sea. This configuration has a resolution of $0.5^{\circ}$ at the equator and is implemented on a quasi-isotropic tripolar grid that avoids a North Pole singularity. At this resolution, mesoscale eddies are represented by an isopycnal mixing/advection parameterization following Gent and McWilliams (1990). In the vertical, 46 levels are used that decrease in resolution with depth $(6 \mathrm{~m}$ at the surface, $250 \mathrm{~m}$ at depth). Vertical eddy viscosity and diffusivity coefficients are computed from a turbulent kinetic energy (TKE) scheme as described in Blanke and Delecluse (1993). We use a filtered free surface (Roullet and Madec 2000), a total variance-diminishing tracer advection scheme (Levitus et al. 2001), and an energy-enstrophy conservation scheme (Arakawa and Lamb 1981) for the momentum equation. A bi-Laplacian diffusion of momentum $\left(-7.8 \times 10^{11} \mathrm{~m}^{4} \mathrm{~s}^{-1}\right.$ at the equator, decreasing with latitude proportionally to $\Delta X^{3}$, where $\Delta X$ is the gridcell width) is applied on geopotential levels, while Laplacian lateral mixing of tracers $\left(1000 \mathrm{~m}^{2} \mathrm{~s}^{-1}\right.$ at the equator, decreasing with latitude proportionally to $\Delta X$ ) is applied along isoneutral surfaces. The northern and southern boundaries of the North Atlantic domain are closed, and salinity and temperature at these boundaries are restored to the vertically structured Levitus et al. (1998) climatology. A buffer zone of 14 grid points is defined at each boundary, with a linear damping time of 3 days at the boundary limit and of 100 days at the ocean limit.

The model is forced with the DFS4.3 atmospheric forcing of Brodeau et al. (2010), which uses 6-hourly air temperature $t_{2}$, specific humidity $q_{2}$, and wind fields $u_{10}$ and $v_{10}$ corrected from the ERA-40 (1958-2002; Uppala et al. 2005). Satellite products of long-/shortwave radiation (1984-2002) and of monthly snow and precipitation 

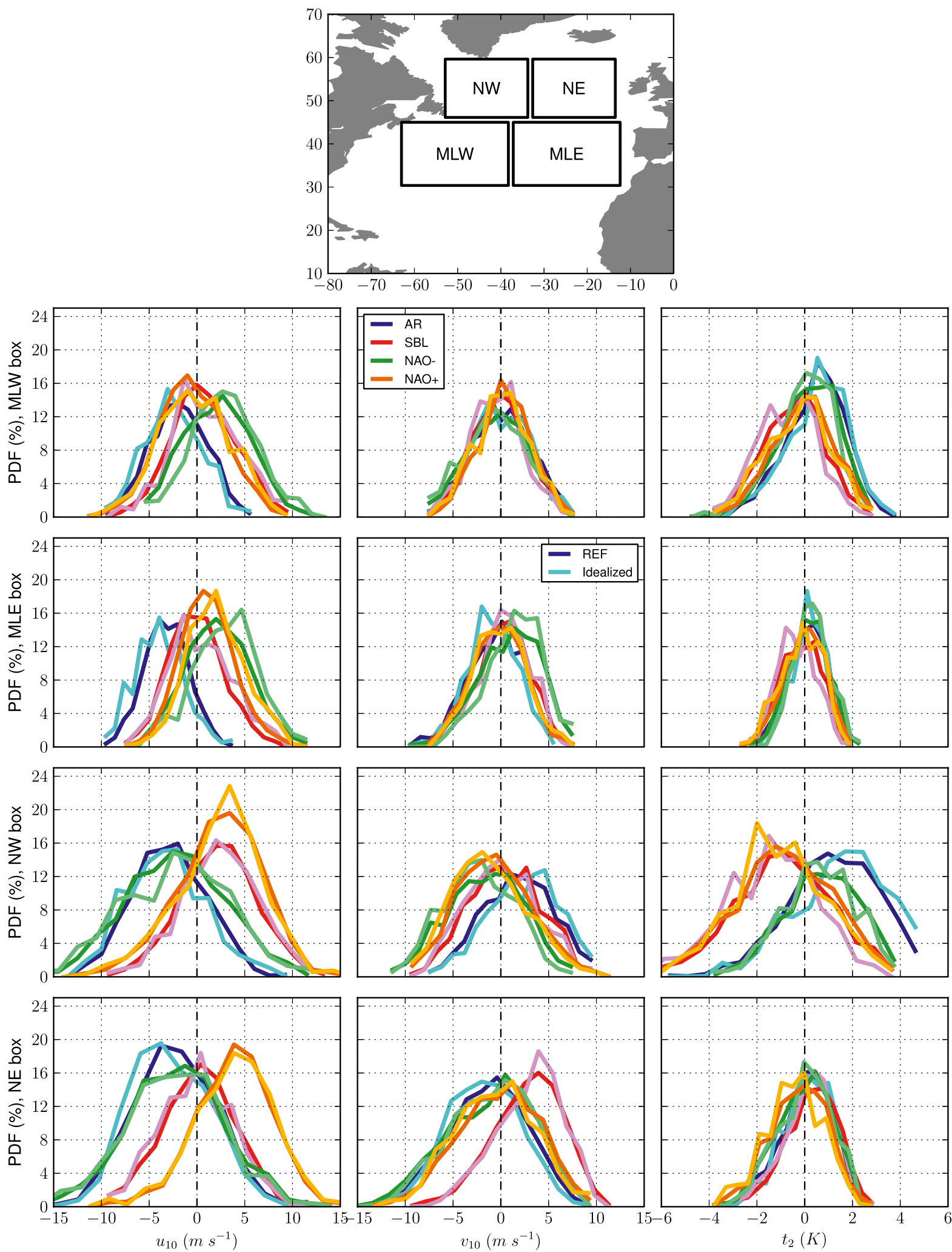

FIG. B1. PDF (\%) for (left) $u_{10}$, (middle) $v_{10}$, and (right) $t_{2}$ in the MLW (top), MLE (upper middle), NW (lower middle), and NE (bottom) Atlantic boxes. Dark colors are the PDFs from the reference forcings, while light colors are used for the idealized ones. 

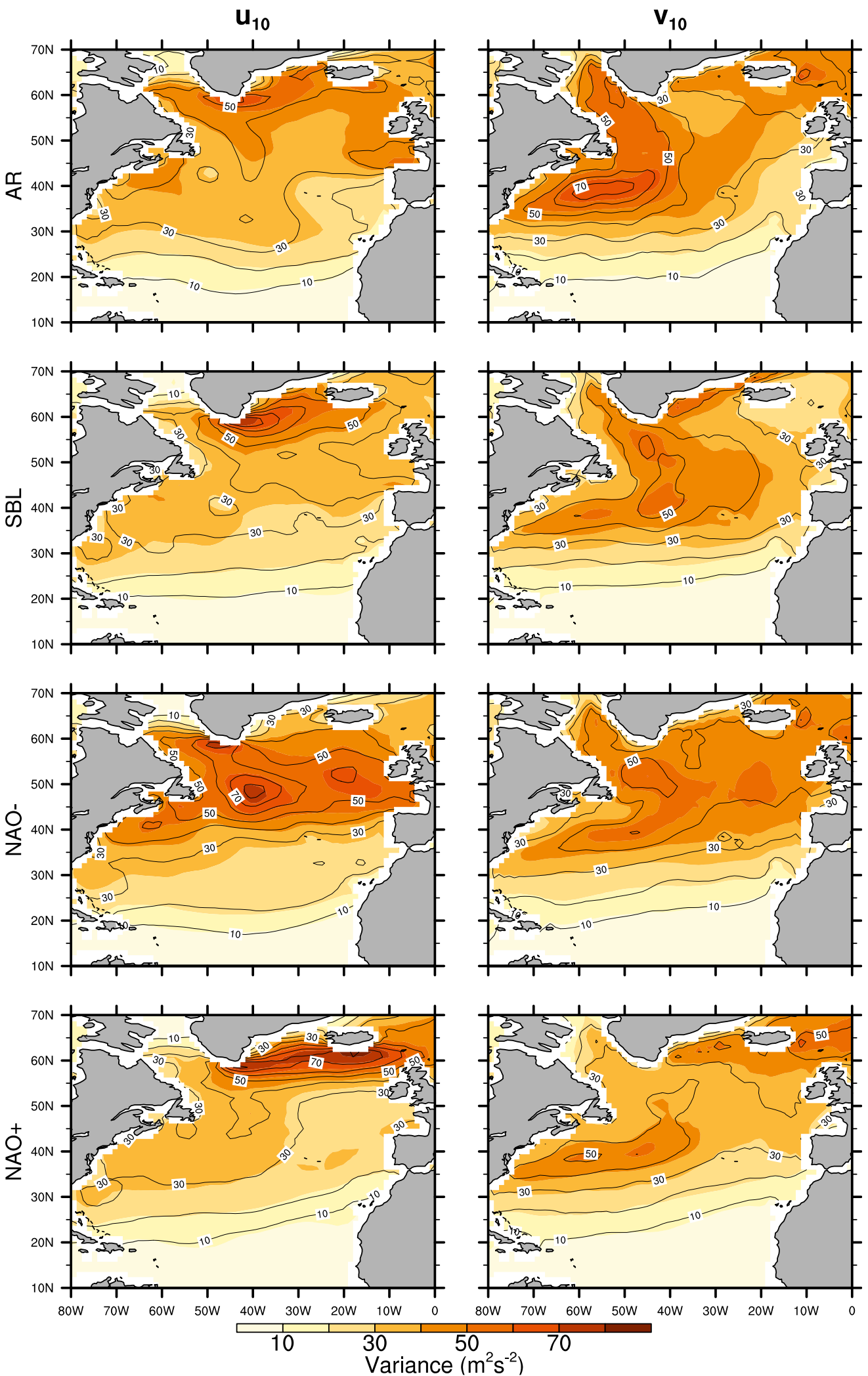

FIG. B2. Winter daily variance of observed (color shading) and reconstructed (black contours) wind components (left) $u_{10}$ and (right) $v_{10}$ within $\mathrm{AR}$ (top), SBL (upper middle), $\mathrm{NAO}^{-}$(lower middle), and $\mathrm{NAO}^{+}$ (bottom). 
(1979-2002) are preferentially used because of their improved quality over their equivalent in reanalysis products (Large and Yeager 2009). Prior to 1984 climatological radiative fluxes are applied and prior to 1979, climatological snow and precipitation are used.

Turbulent fluxes are estimated every 6-h from surface atmospheric-state variables and modeled sea surface temperature (SST) using the bulk formulas described in Large et al. (1997) and Large and Yeager (2004). Modeled sea surface salinity is restored to Levitus et al. (1998) climatology with a restoring coefficient of $166.6 \mathrm{~mm} \mathrm{day}^{-1}$. As DFS4.3 is based on ERA-40, while we computed WRs from the NCEP-NCAR reanalysis, we have checked that there are no discrepancies between the two datasets by comparing the wind anomaly composites of both datasets, which are very similar (not shown).

\section{APPENDIX B}

\section{Validation of the Forcing Construction}

Here, we describe how we verified that the idealized forcing statistics corresponding to each regime are well captured by our construction method. We have first spatially averaged daily DJFM zonal $\left(u_{10}\right)$ and meridional $\left(v_{10}\right)$ wind components as well as air-temperature anomalies $t_{2}$ anomalies over four different regions depicted in Fig. B1: midlatitude western Atlantic (MLW), midlatitude eastern Atlantic (MLE), northwestern Atlantic (NW), and northeastern Atlantic (NE). For each box we have computed the probability density functions (PDFs) within each regime for the DFS4.3 forcing used in REF, which we compared with the PDFs of the idealized forcings computed in the same domain boxes (Fig. B1). The PDFs obtained using the DFS4.3 forcings are consistent with the wind anomalies that characterize winter WRs (Cassou et al. 2011). For instance, the reinforcement of westerlies in the NW and NE boxes associated with the $\mathrm{NAO}^{+}$regime is well captured, and conversely for $\mathrm{NAO}^{-}$.

The PDFs of the idealized forcing generally compare well with the PDFs of the original forcing. This is especially true in the NE and NW boxes, where the differences between the statistics of the reconstructed and original forcing are marginal. In line with the introduction, the NAO asymmetry in $u_{10}$ is striking here. Midlatitude strengthening of the westerlies seems slightly underestimated in the MLE box. For $v_{10}$, significant differences between the regimes are only found in the NW and NE boxes. Notably, the northward shift of midlatitude westerlies particular to SBL conditions is well captured in the NE box. Regarding $t_{2}$, notable differences between the regimes are only found in the NW box, with the negative anomalies during SBL/ $\mathrm{NAO}^{-}$and the positive anomalies during $\mathrm{AR} / \mathrm{NAO}^{+}$ (Fig. 2) that are well captured.

Figure B2 shows the observed winter daily variance of both wind components of each regime and the variance of the idealized forcings. The major features of daily variance can be seen to be well captured by the construction scheme. The regions of high $u_{10}$ variance in the midlatitude westerlies that are particular to the AR, $\mathrm{SBL}$, and $\mathrm{NAO}^{+}$regimes have the correct magnitude, and the southward-shifted pattern of high $\mathrm{NAO}^{-}$variability is well reproduced. In the case of $v_{10}$, which generally shows weaker variance than $u_{10}$, the patterns are also fairly well reproduced, both in terms of spatial scales and amplitudes. The AR pattern of high variability at $40^{\circ} \mathrm{N}$ in the western part of the basin is well captured.

It should be noted that only winter forcings are constructed. The influence of summer forcing is not considered here because the variance of atmospheric forcing is strongest in winter, thereby allowing us to make a more effective and persistent imprint on largescale ocean changes. Furthermore, radiative fluxes (shortwave and longwave), precipitation, and snow are not reconstructed.

\section{REFERENCES}

Anderson, D. L., and P. D. Killworth, 1977: Spin-up of a stratified ocean, with topography. Deep-Sea Res., 24, 709-732.

Arakawa, A., and V. Lamb, 1981: A potential enstrophy and energy conserving scheme for the shallow water equations. Mon. Wea. Rev., 109, 18-36.

Barnston, A., and R. Livezey, 1987: Classification, seasonality and persistence of low-frequency atmospheric circulation patterns. Mon. Wea. Rev., 115, 1083-1126.

Barrier, N., A.-M. Treguier, C. Cassou, and J. Deshayes, 2013: Impact of the winter North-Atlantic weather regimes on subtropical sea-surface height variability. Climate Dyn., 41, 1159-1171.

Bellucci, A., S. Gualdi, E. Scoccimarro, and A. Navarra, 2008: NAO-ocean circulation interactions in a coupled general circulation model. Climate Dyn., 31, 759-777.

Biastoch, A., C. W. Böning, J. Getzlaff, J.-M. Molines, and G. Madec, 2008: Causes of interannual-decadal variability in the meridional overturning circulation of the midlatitude North Atlantic Ocean. J. Climate, 21, 6599-6615.

Blanke, B., and P. Delecluse, 1993: Variability of the tropical Atlantic Ocean simulated by a general circulation model with two different mixed-layer physics. J. Phys. Oceanogr., 23, 1363-1388.

Böning, C. W., M. Scheinert, J. Dengg, A. Biastoch, and A. Funk, 2006: Decadal variability of subpolar gyre transport and its reverberation in the North Atlantic overturning. Geophys. Res. Lett., 33, L21S01, doi:10.1029/2006GL026906.

Brodeau, L., B. Barnier, A.-M. Treguier, T. Penduff, and S. Gulev, 2010: An ERA40-based atmospheric forcing for global ocean 
circulation models. Ocean Modell., 31, 88-104, doi:10.1016/ j.ocemod.2009.10.005.

Cabanes, C., T. Huck, and A. C. De Verdiere, 2006: Contributions of wind forcing and surface heating to interannual sea level variations in the Atlantic Ocean. J. Phys. Oceanogr., 36, 1739-1750.

Cassou, C., L. Terray, J. Hurrell, and C. Deser, 2004: North Atlantic winter climate regimes: Spatial asymmetry, stationarity with time, and oceanic forcing. J. Climate, 17, 1055-1068.

—- M. Minvielle, L. Terray, and C. Périgaud, 2011: A statisticaldynamical scheme for reconstructing ocean forcing in the Atlantic. Part I: Weather regimes as predictors for ocean surface variables. Climate Dyn., 36, 19-39.

Curry, R., and M. McCartney, 2001: Ocean gyre circulation changes associated with the North Atlantic Oscillation. J. Phys. Oceanogr., 31, 3374-3400.

Danabasoglu, G., W. G. Large, and B. P. Briegleb, 2010: Climate impacts of parameterized Nordic sea overflows. J. Geophys. Res., 115, C11005, doi:10.1029/2010JC006243.

Deshayes, J., F. Straneo, and M. A. Spall, 2009: Mechanisms of variability in a convective basin. J. Mar. Res., 67, 273-303.

Dickson, R. R. and J. Brown, 1994: The production of North Atlantic Deep Water: Sources, rates, and pathways. J. Geophys. Res., 99 (C6), 12319-12341.

Eden, C., and T. Jung, 2001: North Atlantic interdecadal variability: Oceanic response to the North Atlantic Oscillation (18651997). J. Climate, 14, 676-691.

— , and J. Willebrand, 2001: Mechanism of interannual to decadal variability of the North Atlantic circulation. J. Climate, 14, 2266-2280.

—, and R. J. Greatbatch, 2003: A damped decadal oscillation in the North Atlantic climate system. J. Climate, 16, 4043-4060.

Fichefet, T., and M. Maqueda, 1997: Sensitivity of a global sea ice model to the treatment of ice thermodynamics and dynamics. J. Geophys. Res., 102 (C6), 12 609-12646.

Gent, P., and J. McWilliams, 1990: Isopycnal mixing in ocean circulation models. J. Phys. Oceanogr., 20, 150-155.

Getzlaff, J., C. W. Böning, C. Eden, and A. Biastoch, 2005: Signal propagation related to the North Atlantic overturning. Geophys. Res. Lett., 32, L09602, doi:10.1029/2004GL021002.

Griffies, S. M., and Coauthors, 2009: Coordinated Ocean-Ice Reference Experiments (COREs). Ocean Modell., 26, 1-46.

Häkkinen, S., and P. B. Rhines, 2004: Decline of subpolar North Atlantic circulation during the 1990s. Science, 304, 555-559.

— _ _ , and D. L. Worthen, 2011a: Atmospheric blocking and Atlantic multidecadal ocean variability. Science, 334, 655-659.

,-- , and $-2011 \mathrm{~b}$ : Warm and saline events embedded in the meridional circulation of the northern North Atlantic. J. Geophys. Res., 116, C03006, doi:10.1029/2010JC006275.

Hátún, H., A. B. Sand $\varnothing$, H. Drange, B. Hansen, and H. Valdimarsson, 2005: Influence of the Atlantic subpolar gyre on the thermohaline circulation. Science, 309, 1841-1844.

Herbaut, C., and M.-N. Houssais, 2009: Response of the eastern North Atlantic subpolar gyre to the North Atlantic Oscillation. Geophys. Res. Lett., 36, L17607, doi:10.1029/ 2009GL039090.

Hong, B. G., W. Sturges, and A. J. Clarke, 2000: Sea level on the U.S. East Coast: Decadal variability caused by open ocean wind-curl forcing. J. Phys. Oceanogr., 30, 2088-2098.

Hurrell, J. W., 1995: Decadal trends in the North Atlantic Oscillation: Regional temperatures and precipitations. Science, 269, 676-679.

Jayne, S. R., and J. Marotzke, 2001: The dynamics of ocean heat transport variability. Rev. Geophys., 39, 385-411.
Jungclaus, J., H. Haak, M. Latif, and U. Mikolajewicz, 2005: Arctic-North Atlantic interactions and multidecadal variability of the meridional overturning circulation. J. Climate, 18, 4013-4031.

Kalnay, E., and Coauthors, 1996: The NCEP/NCAR 40-Year Reanalysis Project. Bull. Amer. Meteor. Soc., 77, 437-471.

Koblinsky, C., 1990: The global distribution of $f / H$ and the barotropic response of the ocean. J. Geophys. Res., 95 (C3), 32133218.

Köhl, A., and D. Stammer, 2008: Variability of the meridional overturning in the North Atlantic from the 50-year GECCO state estimation. J. Phys. Oceanogr., 38, 1913-1930.

Langehaug, H. R., I. Medhaug, T. Eldevik, and O. H. Ottera, 2012: Arctic/Atlantic exchanges via the subpolar gyre. J. Climate, 25, 2421-2439.

Large, W. G. and S. G. Yeager, 2004: Diurnal to decadal global forcing for ocean and sea-ice models: The data sets and flux climatologies. NCAR Tech. Note NCAR/TN-460+STR, 105 pp.

—_, and —_, 2009: The global climatology of an interannually varying air-sea flux data set. Climate Dyn., 33, 341364.

— - G. Danabasoglu, S. C. Doney, and J. C. McWilliams, 1997: Sensitivity to surface forcing and boundary layer mixing in a global ocean model: Annual-mean climatology. J. Phys. Oceanogr., 27, 2418-2447.

Levitus, S., and Coauthors, 1998: Introduction. Vol. 1, World Ocean Database 1998, NOAA Atlas NESDIS 18, 346 pp.

- J. J. Antonov, J. Wang, T. Delworth, K. Dixon, and A. Broccoli, 2001: Anthropogenic warming of Earth's climate system. Science, 292, 267-270.

Lohmann, K., H. Drange, and M. Bentsen, 2009: Response of the North Atlantic subpolar gyre to persistent North Atlantic Oscillation like forcing. Climate Dyn., 32, 273-285.

Madec, G., 2008: NEMO ocean engine. IPSL Note du Pôle de modélisation 27, Version 3.2, 219 pp.

Marshall, J., H. Johnson, and J. Goodman, 2001: A study of the interaction of the North Atlantic Oscillation with ocean circulation. J. Climate, 14, 1399-1421.

Medhaug, I., H. Langehaug, T. Eldevik, T. Furevik, and M. Bentsen, 2012: Mechanisms for decadal scale variability in a simulated Atlantic meridional overturning circulation. Climate Dyn., 39, 77-93.

Michelangi, P.-A., R. Vautard, and B. Legras, 1995: Weather regimes: Recurrence and quasi stationarity. J. Atmos. Sci., 52, 1237-1256.

Minvielle, M., C. Cassou, R. Bourdalle-Badie, L. Terray, and J. Najac, 2011: A statistical-dynamical scheme for reconstructing ocean forcing in the Atlantic. Part II: Methodology, validation and application to high-resolution ocean models. Climate Dyn., 36, 401-417.

Msadek, R., and C. Frankignoul, 2009: Atlantic multidecadal oceanic variability and its influence on the atmosphere in a climate model. Climate Dyn., 33, 45-62.

Pickart, R. S., and M. A. Spall, 2007: Impact of Labrador Sea convection on the North Atlantic meridional overturning circulation. J. Phys. Oceanogr., 37, 2207-2227.

Roullet, G., and G. Madec, 2000: Salt conservation, free surface, and varying levels: A new formulation for ocean general circulation models. J. Geophys. Res., 105 (C10), $23927-$ 23942.

Ruprich-Robert, Y., and C. Cassou, 2013: Combined influences of seasonal east Atlantic pattern and North Atlantic Oscillation 
to excite Atlantic multidecadal variability in a climate model. Climate Dyn., in press.

Rust, H. W., M. Vrac, M. Lengaigne, and B. Sultan, 2010: Quantifying differences in circulation patterns based on probabilistic models: IPCC AR4 multimodel comparison for the North Atlantic. J. Climate, 23, 6573-6589.

Sarafanov, A., A. Falina, A. Sokov, and A. Demidov, 2008: Intense warming and salinification of intermediate waters of southern origin in the eastern subpolar North Atlantic in the 1990s to mid-2000s. J. Geophys. Res., 113, C12022, doi:10.1029/ 2008JC004975.

Scherrer, S., M. Croci-Maspoli, C. Schwierz, and C. Appenzeller, 2006: Two-dimensional indices of atmospheric blocking and their statistical relationship with winter climate patterns in the Euro-Atlantic region. Int. J. Climatol., 26, 233-249, doi:10.1002/ joc. 1250.

Schweckendiek, U., and J. Willebrand, 2005: Mechanisms affecting the overturning response in global warming simulations. J. Climate, 18, 4925-4936.

Smith, R., M. Maltrud, F. O. Bryan, and M. W. Hecht, 2000: Numerical simulation of the North Atlantic Ocean at $1 / 10^{\circ}$. J. Phys. Oceanogr., 30, 1532-1561.

Straneo, F., 2006: Heat and freshwater transport through the central Labrador Sea. J. Phys. Oceanogr., 36, 606-628.
Treguier, A. M., S. Theetten, E. Chassignet, T. Penduff, R. Smith, L. Talley, J. Beismann, and C. Böning, 2005: The North Atlantic subpolar gyre in four high-resolution models. J. Phys. Oceanogr., 35, 757-774.

—, M. H. England, S. R. Rintoul, G. Madec, J. Le Sommer, and J. M. Molines, 2007: Southern Ocean overturning across streamlines in an eddying simulation of the Antarctic Circumpolar Current. Ocean Sci., 3, 491-507.

Uppala, S., and Coauthors, 2005: The ERA-40 Re-Analysis. Quart. J. Roy. Meteor. Soc., 131, 2961-3012.

Vautard, R., 1990: Multiple weather regimes over the North Atlantic: Analysis of precursors and successors. Mon. Wea. Rev., 118, 2056-2081.

Visbeck, M., H. Cullen, G. Krahmann, and N. Naik, 1998: An ocean model's response to North Atlantic Oscillation-like wind forcing. Geophys. Res. Lett., 25, 4521-4524.

Vivier, F., K. Kelly, and L. Thompson, 1999: Contributions of wind forcing, waves, and surface heating to sea surface height observations in the Pacific Ocean. J. Geophys. Res., 104 (C9), 20767-20788.

Zhu, J., and E. Demirov, 2011: On the mechanism of interannual variability of the Irminger Water in the Labrador Sea. J. Geophys. Res., 116, C03014, doi:10.1029/ 2009JC005677. 